\title{
A Percepção de Contadores Sobre a Demonstração dos Fluxos de Caixa no Setor Público Brasileiro
}

\section{The Perception of Accountants on the Cash Flow Statement in the Brazilian Public Sector}

\author{
BRUNO ZAMPROGNO \\ JOÃO EUDES BEZERRA FILHO \\ Fucape Business School
}

\section{RESUMO}

O objetivo desta pesquisa foi verificar a percepção de contadores que atuam com a Contabilidade Aplicada ao Setor Público (CASP) acerca da evidenciação da Demonstração dos Fluxos de Caixa (DFC), conforme modelo da Secretaria do Tesouro Nacional (STN). Para isso, realizou-se pesquisa descritiva, de corte transversal, com abordagem quantitativa. Os dados, obtidos por meio de questionário, foram segregados pela atuação dos respondentes, além de serem agrupados em seis clusters, conforme a similaridade e a consistência das respostas. Em alguns casos, houve opiniões divergentes em relação à $\mathrm{DFC}$, como se esse demonstrativo deveria evidenciar os recursos extraorçamentários e se ele é necessário ou não, além da maioria sugerir que a DFC deveria ter outra forma de apresentação. Espera-se que este estudo contribua com a discussão dos profissionais que atuam, de forma prática ou teórica, com a CASP e que estes ou os órgãos normatizadores, se for o caso, busquem melhorias para as informações divulgadas à sociedade.

Palavras-chave: contabilidade; setor público; demonstração dos fluxos de caixa; percepção de usuários.

\section{Abstract}

The objective of this research was to verify the perception of accountants working with Applied Accounting to the Public Sector (AAPS) about the disclosure of the Cash Flow Statement 
(CFS), according to the National Treasury Secretariat (NTS) model. For this, a descriptive cross-sectional study was carried out with a quantitative approach. The data, obtained by means of a questionnaire, were segregated by the action of the respondents, besides being grouped in six clusters, according to the similarity and the consistency of the answers. In some cases, there were divergent opinions regarding CFS, as if this statement should evidence the extra-budgetary resources and whether it is necessary or not, in addition to the majority suggesting that the CFS should have another form of presentation. It is hoped that this study contributes to the discussion of the professionals who act, in a practical or theoretical way, with AAPS and that these or the regulatory bodies, if applicable, seek improvements to the information disclosed to society.

Keywords: accounting; public sector; cash flow statement; perception of users.

\section{INTRODUÇÃo}

Nas últimas décadas, diversos países experimentaram uma série de mudanças em relação às normas de contabilidade aplicadas ao setor público (HOEK, 2005; CHRISTIAENS; REYNIERS; ROLLÉ, 2010; GROSSI; SOVERCHIA, 2011; ALSHUJAIRI, 2014; AVERSANO; CHRISTIAENS, 2014; CHRISTIAENS; VANHEE; MANES-ROSSI; AVERSANO; CAUWENBERGE, 2015; MUSSARI, 2014; JONES; CARUANA, 2014; OULASVIRTA, 2014a, 2014b; LASWAD; REDMAYNE, 2015; ABEYSINGHE; SAMANTHI, 2016; ADHIKARI; GARSETH-NESBAKK, 2016). No Brasil, o alinhamento às normas internacionais, emitidas pelo International Public Sector Accounting Standards Board, visa melhorar as informações das demonstrações contábeis e a transparência dos entes públicos (CALADO; TEIXEIRA, 2016; FERNANDES; BEZERRA FILHO, 2016).

Nesse processo, os responsáveis pelo registro contábil sequer foram consultados sobre essas mudanças, dado que ocorreram de maneira normativa (CALADO; TEIXEIRA, 2016), o que pode gerar interpretações distintas ou, até mesmo, excludentes entre esses profissionais (MALAQUIAS; MACHADO; SÁ, 2017). Ademais, houve a inclusão da obrigatoriedade da divulgação de novos demonstra- 
tivos, como a Demonstração dos Fluxos de Caixa - DFC (CALADO; TEIXEIRA, 2016), que visa evidenciar a conduta na gestão do patrimônio das entidades (INTERNATIONAL FEDERATION OF ACCOUNTANTS [IFAC], 2016).

Contudo, a adesão em divulgar a DFC pelos entes federados é baixa, pois não teve uma rápida adaptação cultural e no ambiente de trabalho, além de suas informações serem pouco compreensíveis para usuários externos (CALADO; TEIXEIRA, 2016). Nesse contexto, este trabalho teve o objetivo de verificar a percepção de contadores que atuam com a Contabilidade Aplicada ao Setor Público (CASP) acerca da evidenciação da Demonstração dos Fluxos de Caixa (DFC), conforme modelo da Secretaria do Tesouro Nacional (STN).

Estudos anteriores utilizaram relatórios financeiros de empresas para tratar dessa demonstração, sugerindo que a forma de apresentação da DFC pelos métodos direto e indireto pode influenciar nas decisões tomadas pelos usuários (KLAMMER; REED, 1990; GOYAL, 2004; ORPURT; ZANG, 2009; BRADBURY, 2011; KOJIMA, 2012; ZHAO, 2013; ZHAO; EL-MASRY, 2013; RAMLUGUN; HOSANEE, 2014; ABDULLAH; MAJED; AYMEN, 2016). Outros sinalizaram que a desagregação das informações aumenta a confiabilidade de auditores (LIBBY; BROWN, 2013) e afeta a decisão de investidores (BONNER; CLOR-PROELL; KOONCE, 2014), e que os gestores desagregam informações quando lhes é conveniente (LIBBY; BROWN, 2013; BONNER; CLOR-PROELL; KOONCE, 2014).

Outros apontaram que a informação pelos fluxos de caixa tem mais utilidade, relevância e objetividade para tomada de decisão do que as pautadas no regime de competência (SHARMA; ISELIN, 2003a, 2003b). Em contraposição, usuários também podem não se basear nas informações da DFC para tomar decisões e sim em outros relatórios financeiros pautados no regime de competência (KWOK, 2002).

Esta pesquisa se diferencia das anteriores por verificar a forma de apresentação da DFC no setor público, ramo em que não foram observados estudos correlatos durante a revisão de literatura. Este estudo será realizado na Administração Pública brasileira, que possui especificidades em virtude de determinações legais, como a vinculação de recursos à finalidade específica (STN, 2017). 
Ademais, visa contribuir com o debate profissional e acadêmico sobre as mudanças que estão ocorrendo nas normas da CASP, sobre as suas finalidades e se estas estão atingindo seus objetivos. Estudos sobre a percepção de contadores e de usuários das demonstrações contábeis se mostram relevantes no intuito de buscar aprimorar as informações evidenciadas e garantir a sua utilidade. Além desta introdução, este trabalho está dividido em fundamentação teórica, metodologia, análise e discussão dos dados e considerações finais.

\section{REFERENCIAL TEórico}

\subsection{Estudos Sobre Percepção}

Estudos sobre a percepção de contadores e de usuários das informações contábeis se mostram relevantes, por exemplo, ao buscar apontamentos sobre possíveis entraves no processo de elaboração e divulgação das demonstrações contábeis e ao apontar que as informações evidenciadas precisam ser aprimoradas, com o intuito de garantir a sua utilidade. Na sequência, foram apresentadas algumas pesquisas que versam sobre percepção dessas pessoas.

Rosa, Silva e Soares (2015) pesquisaram sobre a percepção de contadores que atuam em prefeituras municipais do estado de Santa Catarina, acerca da implantação de um sistema de custos para a administração pública. Por meio de análise descritiva dos dados, Rosa, Silva e Soares (2015) destacaram que 94\% dos respondentes possuíam graduação ou especialização, que esses contadores reconheceram a importância da implantação de um sistema de custos para apoiar o processo de planejamento e orçamento, assim como para apoiar o controle e as decisões na administração pública, e que o sucesso da implementação depende da experiência e conhecimento desses profissionais.

Piccoli e Klann (2015) buscaram identificar a percepção dos contadores que atuam no setor público em relação às Normas Brasileiras de CASP (NBCASP), em relação ao sistema de informação, a atualização profissional e a mudança de cultura operacional. A partir de um questionário que fora enviado aos profissionais dos municípios da região da Associação de Municípios do Meio Oeste de Santa Catarina, Piccoli e Klann (2015) apontaram 79\% dos respondentes 
possuíam graduação ou especialização, que 50\% dos entrevistados não possuíam amplo conhecimento sobre as NBCASP e que as maiores deficiências estão nos procedimentos a serem adotados a partir das normas 16.9 e 16.10, concluindo que os contadores ainda não estavam aptos a elaborar e analisar as Demonstrações Contábeis Aplicadas ao Setor Público (DCASP).

Calado e Teixeira (2016) procuraram identificar a percepção de contadores que atuam no processo de elaboração e divulgação das DCASP, após a convergência das normas nacionais às internacionais de contabilidade do setor público. Utilizam de questionário como instrumento de coleta de dados e da técnica de análise fatorial exploratória para verificar quais construtos, num total de oito, impactam nesse processo de elaboração e divulgação (CALADO; TEIXEIRA, 2016).

Na pesquisa de Calado e Teixeira (2016), esses oitos construtos foram agrupados em dois fatores: relevância das informações (prazo estabelecido, relação tempo e adaptação, custos dos recursos e adaptação cultural); e adaptação às normas (qualidade da informação, compreensibilidade para usuários internos, compreensibilidade para usuários externos e utilização das informações para tomar decisão). Desses atributos, as menores concordâncias de percepção dos respondentes foram no uso das informações para tomar decisão, nos custos dos recursos, na adaptação cultural e na compreensibilidade para usuários externos, devido a maior variabilidade (CALADO; TEIXEIRA, 2016).

Silva, Niyama e Rodrigues (2016) analisaram a percepção dos participantes do processo normativo do IASB sobre a proposta de revisão da Conceptual Framework for Financial Reporting propostos no Discussion Paper - DP/2013/1. Por meio da análise de conteúdo, Silva, Niyama e Rodrigues (2016) verificaram as respostas de 80 participações sobre 22 pontos de questionamento das nove seções do DP/2013/1.

O nível de concordância com a proposta do IASB foi de $69,72 \%$, seguido por $20,91 \%$ e $9,38 \%$ de opiniões discordantes e parciais, respectivamente (SILVA; NIYAMA; RODRIGUES, 2016). Os argumentos utilizados pelos participantes foram discriminados segundo tipos: "definição", com 2\%; "escopo", com 49\%; "due process", com 
6\%; "efeitos internos e externos", com 7\%; "exemplos", com 9\%; e "sem argumento", com 27\% (SILVA; NIYAMA; RODRIGUES, 2016).

Os resultados do estudo de Silva, Niyama e Rodrigues (2016) evidenciaram que, no geral, os respondentes fazem uso da experiência prática, bem como do que pensam no tocante a determinados assuntos, sem a utilização de argumentos teóricos que dessem suporte a temática analisada. Ademais, Silva, Niyama e Rodrigues (2016) apontaram que as respostas "sem argumento" ocorreram com maior ênfase quando os respondentes concordavam com a questão proposta, sugerindo que é possível que os participantes se sintam desobrigados a argumentarem quando têm posicionamento favorável as alternativas analisadas.

Carvalho Jr., Cornacchione, Rocha e Rocha (2017) buscaram explicar em que extensão os padrões de mapeamento cerebral seguem os padrões comportamentais dos julgamentos de auditores e contadores, quando esses profissionais avaliam evidências para tomar decisões relacionadas à continuidade operacional. Para analisar o comportamento dos julgamentos e os mapas cerebrais cognitivos da amostra de 25 profissionais contábeis, Carvalho Jr. et al. (2017) utilizaram diversos testes estatísticos.

Os participantes apresentaram julgamentos semelhantes em relação à continuidade operacional e maior sensibilidade em relação à análise das informações negativas (CARVALHO Jr. et al., 2017). No entanto, sugerem diferentes formas de raciocínio para atingir essas estimativas, tendo em vista padrões diversos de mapeamento cerebral entre os grupos: o grupo de contadores apresentou conflitos no processo de tomada de decisão e maior esforço cognitivo, enquanto o processamento cerebral dos auditores foi homogêneo (CARVALHO Jr. et al., 2017).

Malaquias, Machado, Sá (2017) analisaram se a interpretação das expressões de incerteza é reduzida, ao longo do tempo, entre discentes do curso de graduação em Ciências Contábeis da Universidade Federal de Uberlândia, levando em consideração se a utilização de expressões desse tipo, em vez de termos mais objetivos, transmite informação de melhor qualidade para os usuários externos. Para isso, Malaquias, Machado, Sá (2017) utilizaram de questionário e de entrevistas para caracterizar os respondentes e verificar a percepção 
deles sobre expressões de incerteza contidas nos pronunciamentos técnicos 38, 39 e 40 do Comitê de Pronunciamentos Contábeis.

Utilizando-se de abordagens quantitativa e qualitativa, Malaquias, Machado, Sá (2017) apontaram que a percepção dos participantes da pesquisa sobre as expressões de incerteza não apresentou diferenças estatisticamente significativas, o que pode indicar a tendência de eliminação de potenciais divergências na interpretação de normas ao longo do tempo. Em dado momento, as possíveis diferenças de interpretação podem existir e a redução dessas divergências pode estar associada, por exemplo, à forma como a estrutura curricular do curso está organizada, ao domínio do conteúdo pelos professores e à clareza de abordagem realizada por esses profissionais em sala de aula (MALAQUIAS; MACHADO; SÁ, 2017).

\subsection{Método Direto X Método Indireto de Apresentação da DFC}

Klammer e Reed (1990) investigaram sobre as vantagens comparativas para apresentar a DFC pelos métodos direto e indireto, utilizando como sujeitos da pesquisa analistas de crédito, divididos em dois grupos, que "concederiam um empréstimo" a uma entidade. A única divergência entre as informações em ambos os grupos era o formato de apresentação da DFC. Mesmo apontando algumas restrições, sugeriram que devido a menor variação dos "empréstimos concedidos" pelos analistas que analisaram o método direto, esse método seria mais apropriado.

Kwok (2002) investigou se oficiais de crédito bancário utilizam informações e relatórios financeiros, destacando em particular informações sobre os fluxos de caixa e a DFC, para tomar decisão de empréstimo, bem como se essas decisões são afetadas por duas formas de apresentação: direta e indireta. Cada um dos 20 participantes, todos de Hong Kong, examinou os relatórios anuais de duas empresas (uma da África do Sul e outra da Nova Zelândia, com padrões contábeis semelhantes aos de Hong Kong), totalizando 40 decisões de empréstimo.

Utilizando-se de análise de protocolo verbal, Kwok (2002) conclui que os participantes, de maneira geral, utilizaram informações fornecidas sobre os fluxos de caixa, sem, contudo, utilizarem a DFC. Nesse estudo, Kwok (2002) apontou que a DFC é supérflua para a 
tomada de decisão, seja pelo método direto ou indireto de apresentação, dado que não contribui para a decisão dos agentes de crédito.

Goyal (2004) examinou as percepções de diversos tipos de usuários em relação ao método mais apresentação da DFC que seria mais útil para a tomada de decisão. As informações dos métodos diferiam apenas pelo formato de apresentação. De cem questionários enviados, 47 foram respondidos. Goyal (2004) conclui que há evidências que, de forma geral, o método direto é percebido como superior ao indireto pelos usuários que participaram da pesquisa.

Orpurt e Zang (2009) exploraram sobre a declaração de órgãos internacionais sobre o valor preditivo dos fluxos de caixa futuros pelo método direto de apresentação da DFC. Utilizando-se de uma amostra de cento e dezenove empresas (seiscentas e quatro observações), pelos resultados combinados de três questões de pesquisa inter-relacionadas, concluíram que existem evidências de que o método direto de apresentação diminui erros de medição e melhoram as previsões futuras, em relação ao método indireto.

Bradbury (2011) fez uma revisão de pesquisas acadêmicas para avaliar qual método de apresentação de DFC possui maior qualidade. Expondo argumentos sobre a habilidade preditiva e custos de preparação dos métodos, por exemplo, destacam que a o método direto, relativamente ao indireto, indica melhor previsão do desempenho futuro, associação mais forte com os preços das ações, e redução da assimetria informacional, destacando problemas de auto seleção das amostras.

Kojima (2012) examinou se o método de apresentação de relatórios financeiros influencia as decisões tomadas por seus usuários, investigando se as duas formas de apresentação dos fluxos de caixa das operações (direta e indireta) influenciam as decisões de empréstimo. Para isso, as informações financeiras de uma hipotética empresa de varejo, foram submetidas a 38 sujeitos, divididos em dois grupos, entre graduados e estudantes de Pós-Graduação em Contabilidade, que com base nos materiais fornecidos, tiveram que tomar uma decisão sobre a capacidade da empresa de atender a futuros serviços de dívida e decidir sobre o tamanho do empréstimo a ser concedido a essa empresa. 
Kojima (2012) aborda que os resultados dos usuários que analisaram o formato direto de apresentação foram mais precisos em relação aos do outro grupo. Seu estudo sugere que o formato de apresentação influencia a tomada de decisão dos usuários em parte, porque o método direto de apresentação não exige cálculos adicionais necessários como no método indireto de apresentação para calcular as informações sobre o fluxo de caixa operacional.

Zhao e El-Masry (2013) estudaram sobre as previsões de analistas quando esses utilizaram a DFC pelo método direto e indireto. Dispondo de relatórios de 217 empresas, sugeriram que as previsões de fluxo de caixa dos analistas são mais precisas quando utilizam o método direto em relação ao método indireto na preparação da demonstração dos fluxos de caixa.

Ramlugum e Hosanee (2014) investigaram sobre o método de apresentação da DFC que é mais relevante, confiável, compreensível e útil para usuários na Maurícia tomarem decisões. De cento e cinquenta questionários enviados, oitenta e um foram respondidos. Os participantes indicaram que possuem uma ligeira preferência pelo método direto, em relação ao indireto, nos aspectos de relevância, confiabilidade e utilidade. No que se refere à compreensão, o indireto foi preferível.

Abdullah, Majed e Aymen (2016) examinaram qual método de apresentação de DFC oferece informações úteis, no que tange às características qualitativas da informação contábil, para professores universitários tomarem decisão, distinguindo esses profissionais em relação aos vínculos que eles possuem com as universidades. De 61 profissionais de quatro universidades jordanianas, 38 participaram da pesquisa e indicaram ter preferência pelo método direto de divulgação.

\subsection{Informação Contábil Agredada X Desagregada}

Libby e Brown (2013) pesquisaram se a desagregação voluntária dos números da demonstração do resultado aumenta a confiabilidade dos subtotais dessa demonstração, dado que auditores experientes permitem menos distorção em números desagregados. Pesquisaram também se a localização da evidenciação dos dados desagregados no demonstrativo ou em nota explicativa modera esse efeito, bem como se há consenso dos auditores sobre essas questões. 
Esse estudo indicou que a natureza das normas, o formato de apresentação e a localização da divulgação da informação podem afetar, em média, os julgamentos dos auditores em relação à materialidade das informações, o que afeta a confiabilidade dos números relatados (LIBBY; BROWN, 2013). Isso sugere que a desagregação voluntária diminui o valor médio do erro tolerado nas demonstrações financeiras correntes, mas ao mesmo tempo diminui o consenso dos auditores. O efeito é substancialmente reduzido se os dados desagregados forem apresentados nas notas. Essa diferença entre os auditores pode resultar de diferenças de crenças sobre a relevância de itens de linha sobre a materialidade (LIBBY; BROWN, 2013).

Bonner, Clor-Proell e Koonce (2014) buscaram responder: se as preferências de desagregação de informações dos gestores variam sistematicamente dependendo do sinal e da magnitude relativa dos itens da demonstração de resultados, ou seja, se a agregação ou desagregação é preferida e se isso depende se os itens são ganhos ou perdas e suas magnitudes relativas correspondentes; se a pressão para relatar de forma transparente modera os efeitos da contabilidade mental sobre as preferências dos gerentes; se os julgamentos de avaliação dos investidores são sistematicamente afetados por apresentações agregadas ou desagregadas, ou seja, se como a preferência de gestores afeta a decisão de investidores (BONNER; CLOR-PROELL; KOONCE, 2014).

Ao realizarem quatro experimentos, com número de sujeitos variável em cada um deles, Bonner, Clor-Proell e Koonce (2014) concluíram que as preferências de desagregação dos gestores são consistentes com as previsões da teoria da contabilidade mental, ou seja, que as preferências dos gerentes pela agregação versus desagregação são sistematicamente influenciadas pelo sinal e pela magnitude relativa do ganho e perda subjacentes, o que, por sua vez, leva a preferir a agregação em alguns casos, mas a desagregação em outros. Ademais, a pressão por um relatório transparente, avaliado pelos investidores, apenas modera parcialmente os efeitos da contabilidade mental nas preferências dos gestores. Se os gerentes sentem mais pressão por transparência optarão por desagregar, enquanto os que sentem menos pressão sobre a transparência continuarão a se envolver na contabilidade mental. Isso revela que os 
gestores individuais experimentam a pressão de transparência de forma diferente (BONNER; CLOR-PROELL; KOONCE, 2014).

\subsection{Outros Estudos Relacionados Publicados no Brasil}

Carvalho et al. (2013) procuraram analisar se a forma de apresentação do Balanço Patrimonial altera a percepção de acadêmicos brasileiros e cabo-verdianos, em relação ao conteúdo informacional. Para isso, aplicaram um mesmo questionário a quatro grupos de alunos de duas universidades, sendo que dois grupos (76 brasileiros e 32 cabo-verdianos) responderam o instrumento de pesquisa analisando o padrão da Comissão de Valores Mobiliários e os outros dois grupos (76 brasileiros e 32 cabo-verdianos), o padrão europeu.

Carvalho et al. (2013) apontaram que esses respondentes tendem a preferir o modelo de apresentação típico de seu país. Ademais, sugeriram que essa subordinação pode afetar na compreensão do conteúdo informacional e na interpretação dos usuários, destacando que há a necessidade de novos estudos sobre o assunto.

Daga, Kruger e Mazzioni (2015) pesquisaram junto a gestores de empresas instaladas em Chapecó/SC sobre a utilidade da DFC. Por meio de pesquisa descritiva, apontaram que, de forma geral, a DFC favorece ao controle e à tomada de decisão, não sendo divulgada apenas para atender as exigências normativas.

Homero Junior (2016) analisou 17 pesquisas brasileiras para desenvolver críticas metodológica e epistemológica sobre experimentos em contabilidade realizados no país, a partir de constructos de pesquisa social. Em relação aos aspectos metodológicos, procurou verificar a validade de construtos internos e externos e apontou, dentre outros aspectos, que há falta de evidências para comprovar a validade dos construtos empregados.

No que tange aos aspectos epistemológicos, Homero Junior (2016) baseou-se em quatro fundamentos (abordagem behaviorista; subjetividade; desconsideração de especificidades culturais e históricas; e lógica de controle de seres humanos). Sobre esses aspectos, argumentou, de forma geral, que faltam concepções sociais, que não houve observância as especificidades culturais e históricas e que há necessidade de independência e de objetividade nas pesquisas. 
Homero Junior (2016), por fim, aponta que há uma maior necessidade de engajamento de pesquisadores e de participantes nas pesquisas, de forma a compreender o contexto social envolvido e que os experimentos com premissas positivistas devem ser menos experimentais.

\subsection{Ingressos e Desembolsos Públicos}

Os ingressos e os desembolsos nos cofres públicos têm natureza orçamentária ou extraorçamentária e podem ser efetivos ou não (STN, 2017). As receitas orçamentárias viabilizam a efetivação de políticas públicas em dado exercício, representam os recursos arrecadados de forma originária ou derivada e, em geral, estão previstas no orçamento do ente público (STN, 2017).

As receitas extraorçamentárias constituem recursos de terceiros que transitoriamente estão sob o controle do ente público e cuja arrecadação e devolução não dependem de autorização legislativa (BEZERRA FILHO, 2013; STN, 2017). Alguns desses ingressos extraorçamentários, como os depósitos em caução, podem vir a compor o orçamento público, caso ocorra descumprimento de cláusula de acordo contratual pelo contratado (BEZERRA FILHO, 2013).

As despesas orçamentárias de um exercício financeiro dependem de autorização legislativa para serem executadas, seja por meio do orçamento ou dos créditos adicionais, e, de forma geral, são destinadas à manutenção das atividades do ente público e às demandas econômicas e sociais da sociedade (BEZERRA FILHO, 2013; STN, 2017). As extraorçamentárias não dependem de autorização legislativa e compreendem a saída de valores de terceiros (como as cauções), o pagamento dos restos a pagar, o recolhimento de retenções ou consignações e o pagamento de operações de crédito por antecipação de receita orçamentária (BEZERRA FILHO, 2013; STN, 2017).

\subsection{Atual estrutura da DFC aplicada ao Setor Público}

A atual estrutura da DFC aplicada ao setor público é composta por: Quadro Principal; Quadro de Receitas Derivadas e Originárias; Quadro de Transferências Recebidas e Concedidas; Quadro de Desembolsos de Pessoal e Demais Despesas por Função; e Quadro de Juros e Encargos da Dívida (STN, 2017). O Quadro Principal da 
DFC deve evidenciar a movimentação financeira da conta "Caixa e Equivalentes de Caixa" de cada exercício de referência pelo método direto sem, contudo, fazer a distinção dos fluxos de atividades segundo o mecanismo de Fonte / Destinação de Recursos, que serve para identificar se os recursos são ou não vinculados à dada finalidade, sendo tratado como informação complementar, para simplificar o Plano de Contas Aplicado ao Setor Público - PCASP (STN, 2017).

Para identificar os fluxos de atividades, o Quadro Principal é subdividido em atividades operacionais, de investimentos e de financiamentos, segundo seus ingressos e desembolsos (STN, 2017). Destaca-se que, para as atividades operacionais, os ingressos são segregados em dois campos, "receitas derivadas e originárias" e "transferências correntes recebidas", enquanto os desembolsos em três, "pessoal e demais despesas", "juros e encargos da dívida" e "transferências concedidas" (STN, 2017).

Os demais quadros supracitados são anexos que complementam o Quadro Principal e, basicamente, servem para detalhar os campos das atividades operacionais que dão nome a esses quadros anexos (STN, 2017). Destaca-se que o Quadro de Receitas Derivadas, o Quadro de Transferências Recebidas e Concedidas e Originárias e o Quadro de Desembolsos de Pessoal e Demais Despesas por Função atendem o exigido na Lei $\mathrm{n}^{\mathrm{o}} 4.320$, Art. $2^{\underline{o}}$, $\S 1^{\underline{0}}$, I, mas isso não permite a integração com o estabelecido no Art. 52, II, da LRF, talvez pelo fato desse demonstrativo possuir natureza financeira e não orçamentária. Na elaboração de todos esses quadros são utilizadas as contas da Classe 6 do PCASP, à exceção das intraorçamentárias, como forma de consolidar as contas do ente, sem o efeito da dupla contagem (STN, 2017).

\section{Metodologia}

Para verificar a percepção de distintos contadores que atuam com a CASP acerca da forma de apresentação da DFC, conforme modelo da STN, foi realizada pesquisa descritiva, de corte transversal, com abordagem quantitativa. A coleta de dados foi realizada por meio de questionário online, organizado em três partes, das quais duas, sobre o perfil dos respondentes e sobre a percepção dos contadores sobre a DFC, foram analisadas nesta pesquisa. 
Dos doze itens sobre o perfil dos respondentes (primeira parte), dez foram tratados: gênero, faixa etária, grau de instrução, tempo de formação no ensino superior, servidor público ou não, tempo de experiência no setor público, atuação em relação à CASP, tempo de atuação com CASP, ente federativo de atuação e região do país. A "formação no ensino superior" foi utilizada apenas como filtro e o item "atua ou não com a CASP" foi ignorado, pela duplicidade com "atuação em relação à CASP". O "grau de instrução", a "atuação em relação à CASP" e o fato de ser ou não servidor público também foram parâmetros de filtro das respostas.

A terceira parte, sobre a percepção dos contadores, com trinta variáveis, foi apresentada no Quadro 1. Nesse quadro, pode-se observar que cada afirmativa recebeu uma abreviatura.

Quadro 1 - Itens utilizados para captar a percepção dos respondentes

\begin{tabular}{|l|l|}
\hline Variável & Afirmativa \\
\hline PERC01a & $\begin{array}{l}\text { A qualidade das informações das Demonstrações Contábeis } \\
\text { Aplicadas ao Setor Público Brasileiro melhorou com a inclusão } \\
\text { da DFC, conforme modelo do MCASP/IPC 08. }\end{array}$ \\
\hline $\begin{array}{l}\text { PERC02a, } \\
\text { b }\end{array}$ & $\begin{array}{l}\text { A qualidade das informações da DFC, conforme modelo do } \\
\text { MCASP/IPC 08, é adequada com o seu papel informacional. }\end{array}$ \\
\hline $\begin{array}{l}\text { PERC03a, } \\
\text { b, c }\end{array}$ & $\begin{array}{l}\text { A qualidade informativa da DFC, conforme modelo do MCASP/ } \\
\text { IPC 08, é adequada para a tomada de decisão. }\end{array}$ \\
\hline PERC04a & $\begin{array}{l}\text { As informações da DFC, conforme modelo do MCASP/IPC 08, } \\
\text { são compreensíveis para usuários internos. }\end{array}$ \\
\hline PERC05a & $\begin{array}{l}\text { As informações da DFC, conforme modelo do MCASP/IPC 08, } \\
\text { são utilizadas pelos gestores do respectivo Ente Público para } \\
\text { tomar decisão. }\end{array}$ \\
\hline PERC06a & $\begin{array}{l}\text { As informações da DFC, conforme modelo do MCASP/IPC 08, } \\
\text { são utilizadas pelos servidores do respectivo Ente Público para } \\
\text { saber sobre os ingressos e os desembolsos de recursos. }\end{array}$ \\
\hline PERC07a & $\begin{array}{l}\text { As informações da DFC, conforme modelo do MCASP/IPC 08, } \\
\text { são utilizadas pelos mecanismos de Controle Interno do respec- } \\
\text { tivo Ente Federativo. }\end{array}$ \\
\hline
\end{tabular}




\begin{tabular}{|c|c|}
\hline PERC08 $^{\mathrm{a}}$ & $\begin{array}{l}\text { As informações da DFC, conforme modelo do MCASP/IPC 08, } \\
\text { são compreensíveis para usuários externos. }\end{array}$ \\
\hline PERC09a & $\begin{array}{l}\text { As informações da DFC, conforme modelo do MCASP/IPC 08, } \\
\text { são utilizadas por investidores e credores do respectivo Ente } \\
\text { Federativo. }\end{array}$ \\
\hline PERC10 & $\begin{array}{l}\text { As informações da DFC, conforme modelo do MCASP/IPC 08, } \\
\text { são utilizadas pelos mecanismos de Controle Externo do respec- } \\
\text { tivo Ente Federativo. }\end{array}$ \\
\hline PERC11 ${ }^{\mathrm{a}}$ & $\begin{array}{l}\text { As informações da DFC, conforme modelo do MCASP/IPC 08, } \\
\text { são utilizadas pelos mecanismos de Controle Social do ente. }\end{array}$ \\
\hline PERC12 ${ }^{\mathrm{b}}$ & $\begin{array}{l}\text { O atual modelo de DFC, conforme modelo do MCASP/IPC 08, } \\
\text { é adequado para representar as especificidades do setor público } \\
\text { brasileiro. }\end{array}$ \\
\hline PERC13 $3^{b}$ & $\begin{array}{l}\text { A DFC, conforme modelo do MCASP/IPC 08, permite identificar } \\
\text { as Fontes/Destinação de recursos. }\end{array}$ \\
\hline PERC14 & $\begin{array}{l}\text { A DFC, conforme modelo do MCASP/IPC 08, permite identificar } \\
\text { os fluxos de recursos, por meio do mecanismo Fontes/Destina- } \\
\text { ção de recursos. }\end{array}$ \\
\hline PERC15 ${ }^{\mathrm{b}}$ & A DFC deve identificar os recursos orçamentários. \\
\hline PERC16 ${ }^{\mathrm{b}}$ & A DFC deve identificar os recursos extraorçamentários. \\
\hline PERC17b & A DFC deve identificar os recursos ordinários. \\
\hline PERC18 ${ }^{\mathrm{b}}$ & A DFC deve identificar os recursos vinculados. \\
\hline PERC19b & $\begin{array}{l}\text { A atual estrutura de DFC, conforme modelo do MCASP/IPC 08, } \\
\text { permite segregar os recursos ordinários dos vinculados. }\end{array}$ \\
\hline PERC20c & $\begin{array}{l}\text { A forma de apresentação da DFC, conforme modelo do MCASP/ } \\
\text { IPC } 08 \text {, é adequada, clara e objetiva. }\end{array}$ \\
\hline PERC21 ${ }^{\mathrm{c}}$ & A DFC deveria ter outra forma de representação. \\
\hline $\begin{array}{l}\text { PERC22 } \\
\text { c }\end{array}$ & $\begin{array}{l}\text { A forma de apresentação da DFC, conforme modelo do MCASP/ } \\
\text { IPC 08, influencia na compreensão do conteúdo informacional. }\end{array}$ \\
\hline PERC23 $3^{\mathrm{b}}$ & $\begin{array}{l}\text { A forma de apresentação da DFC, conforme modelo do MCASP/ } \\
\text { IPC 08, influencia no julgamento dos usuários na tomada de } \\
\text { decisão. }\end{array}$ \\
\hline PERC24c & $\begin{array}{l}\text { Devido ao efeito propriedade (supervalorização do que se tem } \\
\text { ou daquilo que se detêm), os usuários das informações contábeis } \\
\text { tendem a preferir escolher o modelo de representação da DFC } \\
\text { que eles conhecem. }\end{array}$ \\
\hline
\end{tabular}




\begin{tabular}{|l|l|}
\hline PERC25 $^{c}$ & $\begin{array}{l}\text { É possível identificar a situação de liquidez do Ente Federativo } \\
\text { por meio da DFC, conforme modelo do MCASP/IPC 08. }\end{array}$ \\
\hline PERC26 $^{\text {d }}$ & Se a DFC fosse facultativa, não faria. \\
\hline PERC27 $^{d}$ & A DFC é desnecessária. \\
\hline PERC28 $^{d}$ & A DFC é feita por obediência normativa. \\
\hline PERC29 $^{d}$ & A DFC é feita para permitir controle gerencial. \\
\hline PERC30 $^{d}$ & $\begin{array}{l}\text { Os órgãos de controle (interno e externo) são responsáveis para } \\
\text { tomar providências para melhorar as informações contábeis. }\end{array}$ \\
\hline
\end{tabular}

Fonte: Calado e Teixeira (2016), Carvalho, Silva, Mendes e Silva (2013), Daga, Kruger e Mazzioni (2015) e STN (2017).

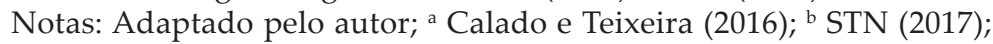
${ }^{c}$ Carvalho et al. (2013); e ${ }^{d}$ Daga et al. (2015).

Cada uma dessas variáveis de percepção foi relacionada à uma escala de Likert de cinco pontos: 1 - discordo totalmente; 2 - discordo parcialmente; 3 - não concordo, nem discordo; 4 - concordo parcialmente; e 5 - concordo totalmente (MARÔCO, 2014).

O público-alvo desta pesquisa, a exemplo de estudos citados no referencial teórico que foram destinados a tipos específicos de usuários, foram contadores que atuam com a CASP, seja de forma prática ou teórica. Estes foram subdivididos em três grupos: grupo 1 - servidores públicos (exceto professores universitários) que atuam no processo de elaboração e/ou divulgação das demonstrações contábeis, com Orçamento Aplicado ao Setor Público, com atividades de Controle Interno ou Controle Externo na Administração Pública e outras atividades afins, relacionadas à CASP; grupo 2 - pesquisadores e professores universitários (servidores públicos ou não) que ministram estudos e/ou aulas relacionadas à CASP; e grupo 3 - profissionais liberais (que não são servidores públicos) que prestam serviços de assessoria ou consultoria relacionados à CASP.

O link de acesso fora disponibilizado via e-mail e inicialmente a coleta de dados ocorreu no período de 09/02/2017 à 26/02/2017, obtendo 74 respostas. Posteriormente, com o propósito de aumentar a amostra inicial, o prazo foi reaberto de 04/04/2017 a 09/05/2017, totalizando 100 participações, das quais 80 foram validadas. 
Os dados referentes a todas as variáveis analisadas foram tabulados. Para verificar a tendência central das respostas dos participantes em relação à percepção deles sobre a DFC, foi utilizada a mediana, tendo em vista que a escala de Likert é do tipo ordinal e que essa é a medida estatística apropriada para dados desse tipo (MARÔCO, 2014). O teste de Kruskal-Wallis e a correlação de Spearman foram utilizados para verificar, respectivamente, as respostas dos grupos e a associação entre a atuação dos participantes e as respostas às variáveis de percepção sobre a DFC. A correlação de Spearman foi testada também para verificar se há associação entre as variáveis de percepção, para auxiliar na análise seguinte: de clusters.

As variáveis de percepção foram agrupadas naturalmente segundo a semelhança das respostas, por meio da técnica hierárquica de agrupamento de clusters. Essa técnica permitiu identificar a relação estrutural entre essas variáveis e complementar as análises do teste de Kruskal-Wallis. Para garantir a confiabilidade dos dados (RODRIGUES; PAULO, 2012) e consequentemente a estrutura mais adequada de representação das variáveis de percepção, foi verificada a consistência interna das respostas de cada grupo formado, por meio do alfa de Cronbach $(\alpha)$.

\section{Análise E Discussão Dos Resultados}

\subsection{Perfil dos Respondentes}

A amostra deste estudo, conforme Tabela 1, é, de maneira geral, homogênea. Destaca-se que a metade atua na região nordeste do país e, dos que são servidores públicos, 32,31\% (21 de 65) atuam como pesquisador ou professor universitário. Observa-se também que $61,25 \%$ são do gênero masculino e que apenas $6(7,5 \%)$ respondentes não iniciaram ou concluíram um curso de pós graduação. 
Tabela 1 - Características da amostra

\begin{tabular}{|c|c|c|c|c|c|}
\hline GÊNERO & Masculino & $\%$ & Feminino & $\%$ & Total \\
\hline Total & 49 & 61,25 & 31 & 38,75 & 80 \\
\hline \multicolumn{6}{|l|}{ FAIXA ETÁRIA (mínima $=24 ;$ máxima $=63$ ) } \\
\hline Até 30 anos & 5 & 6,25 & 1 & 1,25 & 6 \\
\hline De 31 a 40 anos & 14 & 17,50 & 8 & 10,00 & 22 \\
\hline De 41 a 50 anos & 19 & 23,75 & 14 & 17,50 & 33 \\
\hline De 51 a 60 anos & 10 & 12,50 & 5 & 6,25 & 15 \\
\hline De 61 a 70 anos & 1 & 1,25 & 3 & 3,75 & 4 \\
\hline \multicolumn{6}{|l|}{ GRAU DE INSTRUÇÃO } \\
\hline Ensino superior concluído & 4 & 5,00 & 2 & 2,50 & 6 \\
\hline Especialização/MBA em andamento & 1 & 1,25 & 0 & 0,00 & 1 \\
\hline Especialização/MBA concluído & 12 & 15,00 & 13 & 16,25 & 25 \\
\hline Mestrado em andamento & 8 & 10,00 & 6 & 7,50 & 14 \\
\hline Mestrado concluído & 19 & 23,75 & 7 & 8,75 & 26 \\
\hline Doutorado em andamento & 2 & 2,50 & 0 & 0,00 & 2 \\
\hline Doutorado concluído & 3 & 3,75 & 3 & 3,75 & 6 \\
\hline \multicolumn{6}{|l|}{ SERVIDOR (A) PÚBLICO (A) } \\
\hline Sim & 44 & 55,00 & 21 & 26,25 & 65 \\
\hline Não & 5 & 6,25 & 10 & 12,50 & 15 \\
\hline \multicolumn{6}{|l|}{ ATUAÇÃO } \\
\hline $\begin{array}{l}\text { Servidor público (exceto professor } \\
\text { universitário) }\end{array}$ & 29 & 36,25 & 15 & 18,75 & 44 \\
\hline $\begin{array}{l}\text { Professor universitário (servidor público ou } \\
\text { não) }\end{array}$ & 16 & 20,00 & 7 & 8,75 & 23 \\
\hline Profissionais liberais - assessoria/consultoria & 4 & 5,00 & 9 & 11,25 & 13 \\
\hline \multicolumn{6}{|l|}{ ENTE FEDERATIVO DE ATUAÇÃO } \\
\hline Municípios & 12 & 15,00 & 16 & 20,00 & 28 \\
\hline Estado/Distrito Federal & 17 & 21,25 & 11 & 13,75 & 28 \\
\hline União & 20 & 25,00 & 4 & 5,00 & 24 \\
\hline \multicolumn{6}{|l|}{ REGIÃO } \\
\hline Norte & 0 & 0,00 & 0 & 0,00 & 0 \\
\hline Nordeste & 30 & 37,50 & 10 & 12,50 & 40 \\
\hline Centro-Oeste & 5 & 6,25 & 8 & 10,00 & 13 \\
\hline Sul & 2 & 2,50 & 2 & 2,50 & 4 \\
\hline Sudeste & 12 & 15,00 & 11 & 13,75 & 23 \\
\hline
\end{tabular}

Fonte: Dados da pesquisa. 
Na Tabela 2, observa-se que os tempos de formação dos respondentes no ensino superior (TemForm), de experiência/serviço no setor público (TemServSP) e de atuação com CASP (TemAtCASP) possui elevada dispersão, dado que o coeficiente de variação dos três parâmetros é superior a 30\%. Isso implica numa representatividade ruim para a média como medida de posição, conforme abordam Martins e Domingues (2011).

Tabela 2 - Tempo de experiência profissional em anos completos

\begin{tabular}{l|l|l|l}
\hline Medida Estatística & TemForm & TemServSP & TemAtCASP \\
\hline Mínimo & 0 & 2 & 0 \\
\hline Máximo & 39 & 35 & 35 \\
\hline Soma & 1.261 & 1.304 & 1.055 \\
\hline Média & 15,76 & 16,30 & 13,19 \\
\hline Erro padrão & 1,02 & 0,96 & 0,88 \\
\hline Desvio padrão & 9,09 & 8,54 & 7,87 \\
\hline Mediana & 15,00 & 16,00 & 11,00 \\
\hline Moda & 17,00 & 20,00 & 10,00 \\
\hline Coeficiente de Variação & $57,66 \%$ & $52,42 \%$ & $59,66 \%$ \\
\hline Curtose & 0,36 & $-0,76$ & 0,12 \\
\hline Assimetria & 0,82 & 0,33 & 0,72 \\
\hline Nível de confiança (95,00\%) & 2,02 & 1,90 & 1,75 \\
\hline
\end{tabular}

Fonte: Dados da pesquisa.

Nota-se que a média e a mediana desses três itens são próximas e que o tempo de 10 anos foi o mais frequente para a atuação com CASP, que difere da moda do tempo de experiência/serviço no setor público. Destaca-se que há pelo menos uma pessoa que não completou um ano de atuação com a CASP. Essas observações permitem afirmar que a amostra, em relação ao tempo de experiência profissional, é bem diversificada.

\subsection{Percepção dos Respondentes}

Após aplicar o teste de Kruskal-Wallis com as variáveis agrupadas pela atuação dos respondentes, foram aplicadas a correlação de Spearman e a análise de clusters. Para simplificar a apresentação 
dos dados, esta subseção foi subdividida segundo os agrupamentos formados. Os agrupamentos foram testados com o intuito de buscar uma configuração que não permitia que uma das trinta variáveis ficasse isolada em uma das ramificações dos clusters. Dessa forma, começando por dois agrupamentos, contatou-se que a formatação mais consistente para representar essas variáveis foi a que gerou seis clusters, tendo em vista os valores do $\alpha$ desses agrupamentos.

A configuração com sete clusters gerou um agrupamento, formado pela PERC25 e PERC29, com $\alpha<60 \%$. A partir de oito clusters foram gerados agrupamentos com variáveis isoladas.

No Gráfico 1, é possível identificar os seis clusters formados. Esses agrupamentos são analisados nas seis subseções seguintes.

Gráfico 1 - Clusters formados com as variáveis de percepção

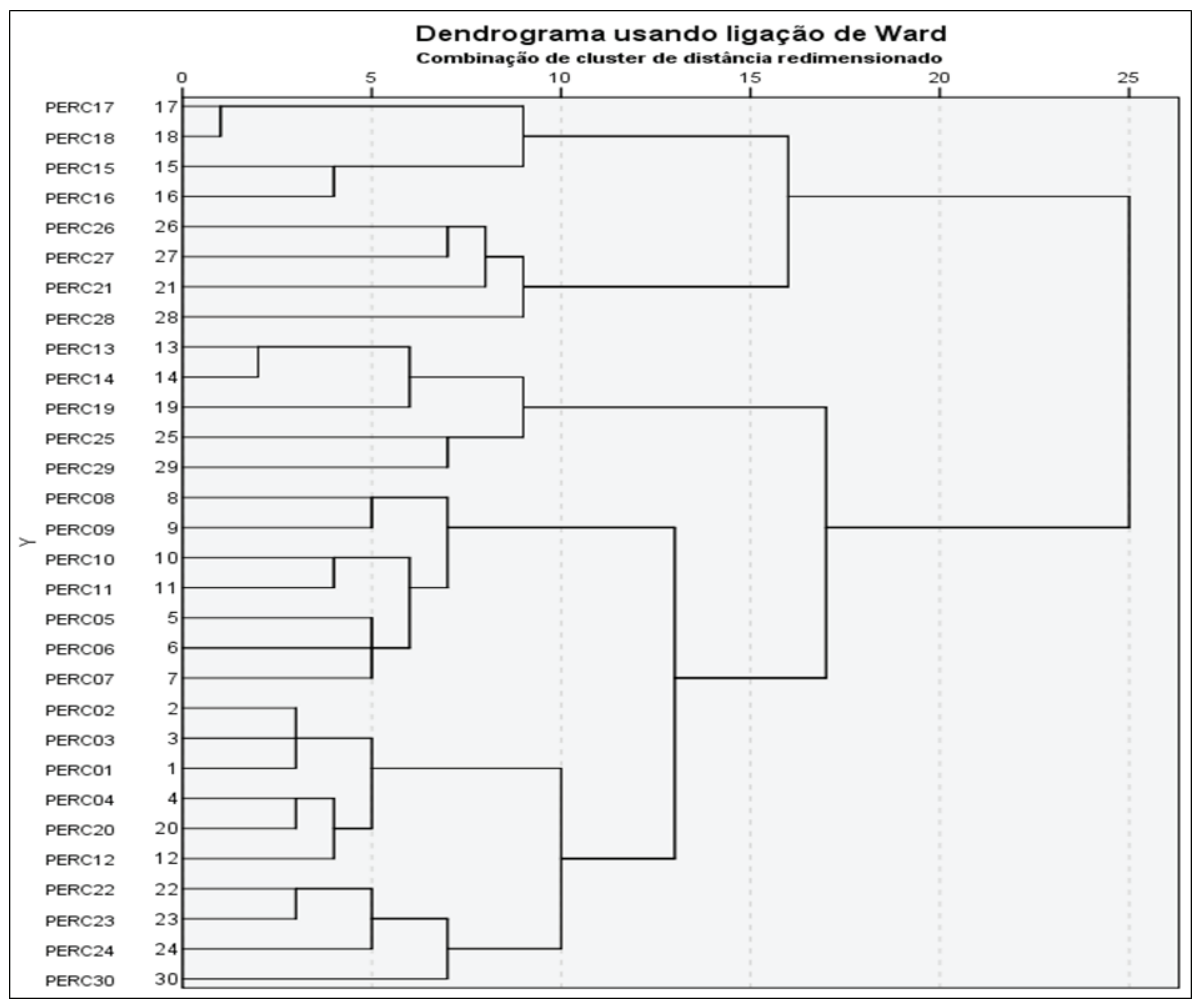

Fonte: Dados da pesquisa. 


\subsubsection{Agrupamento 1}

A Tabela 3 apresenta o primeiro cluster formado. Esse agrupamento, composto pelas variáveis PERC01, PERC02, PERC03, PERC04, PERC12 e PERC20, representa, de forma geral, a percepção dos profissionais sobre a qualidade informacional do atual modelo da DFC/STN, sobre sua compreensibilidade para usuários internos e sobre a representação de especificidades do setor público brasileiro nesse demonstrativo. $\mathrm{O} \alpha$ desse agrupamento foi igual a 0,932 , o que garante elevada confiabilidade das respostas dos dados.

É possível verificar que a maioria dos respondentes (57) concorda com a melhoria na qualidade das informações das DCASP com a inclusão da DFC, conforme modelo da STN (PERC01) enquanto onze discordam. A mediana dos três grupos para essa variável foi a classe 4 (concorda parcialmente) e pode-se afirmar que esses grupos foram gerados de populações com a mesma distribuição $\left(\mathrm{H}_{0}\right)$, dado que $p=0,402>0,05$ de significância.

Tabela 3 - Cluster 1: qualidade informacional interna

\begin{tabular}{|c|c|c|c|c|c|}
\hline \multirow[b]{2}{*}{ Itens } & \multirow[b]{2}{*}{ Grupo } & \multirow{2}{*}{\multicolumn{2}{|c|}{ Atuação }} & Likert & \multirow{2}{*}{ Mediana } \\
\hline & & & & \begin{tabular}{|l|l|l|l|l|}
1 & 2 & 3 & 4 & 5 \\
\end{tabular} & \\
\hline \multirow{7}{*}{ 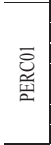 } & 1 & Servidor público (excet & professor universitário) & $\begin{array}{llllll}2 & 2 & 9 & 15 & 16\end{array}$ & 4 \\
\hline & 2 & Professor universitáric & blico or & $\begin{array}{lllll}1 & 2 & 1 & 10 & 9\end{array}$ & 4 \\
\hline & 3 & Profissionais liberais & cesoriancltori & $\begin{array}{lllll}2 & 2 & 2 & 3 & 4\end{array}$ & 4 \\
\hline & \multicolumn{3}{|c|}{ TOTAL } & 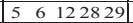 & 4 \\
\hline & Kruskal-Wallis Test & Chi-Square $=$ & Asymp. Sig. $=$ & Ex. Sig. = & 0,402 \\
\hline & Median Test & Chi-Square $=$ & Asymp. Sig. $=$ & Ex. Sig. $=$ & 0,903 \\
\hline & Rô de Spearman & \multirow{4}{*}{\multicolumn{2}{|c|}{$\begin{array}{l}\text { Coeficiente de Correlação com Atuação }=-0,061 \\
\text { Servidor público (exceto professor universitário) } \\
\text { Professor universitário (servidor público ou não) } \\
\text { Profissionais liberais - assessoria/consultoria }\end{array}$}} & Sig. $(2$ ext. $)=$ & 0,590 \\
\hline \multirow{7}{*}{ 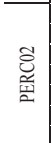 } & 1 & & & $\begin{array}{lllll}2 & 2 & 6 & 22 & 12\end{array}$ & 4 \\
\hline & 2 & & & $\begin{array}{llllll}0 & 4 & 3 & 11 & 5\end{array}$ & 4 \\
\hline & 3 & & & $\begin{array}{lllll}0 & 7 & 1 & 0 & 5\end{array}$ & 2 \\
\hline & \multicolumn{3}{|c|}{ TOTAL } & \begin{tabular}{|llll|l}
2 & 13 & 10 & 33 & 22
\end{tabular} & 4 \\
\hline & Kruskal-Wallis Test & Chi-Square $=$ & Asymp. Sig. $=$ & Ex. Sig. $=$ & 0,343 \\
\hline & Median Test & Chi-Square $=$ & Asymp. Sig. $=$ & Ex. Sig. $=$ & 0,584 \\
\hline & & Coeficiente de Correlaça & com Atuação $=$ & Sig. $(2$ ext. $)=$ & 0,162 \\
\hline \multirow{7}{*}{ 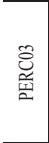 } & 1 & \multirow{3}{*}{\multicolumn{2}{|c|}{$\begin{array}{l}\text { Servidor público (exceto professor universitário) } \\
\text { Professor universitário (servidor público ou não) } \\
\text { Profissionais liberais - assessoria/consultoria }\end{array}$}} & $\begin{array}{|lllll|}3 & 3 & 7 & 19 & 12\end{array}$ & 4 \\
\hline & 2 & & & $\begin{array}{lllll}1 & 4 & 1 & 14 & 3\end{array}$ & 4 \\
\hline & 3 & & & $\begin{array}{lllll}1 & 4 & 2 & 5 & 1\end{array}$ & 3 \\
\hline & \multicolumn{3}{|c|}{ TOTAL } & $\begin{array}{|lllll|}5 & 11 & 10 & 38 & 16\end{array}$ & 4 \\
\hline & Kruskal-Wallis Test & Chi-Square $=$ & Sig. $=$ & Ex. Sig. $=$ & 0,134 \\
\hline & Median & Chi-Square $=$ & Asymp. Sig. $=$ & Ex. Sig. $=$ & 0,203 \\
\hline & Rô de Spea & Coeficiente de Correlaça & com Atuação $=$ & Sig. $(2$ ext. $)=$ & 0,070 \\
\hline \multirow{7}{*}{$\begin{array}{l}\text { 总 } \\
\text { 兽 } \\
\text { d }\end{array}$} & 1 & \multirow{3}{*}{\multicolumn{2}{|c|}{$\begin{array}{l}\text { Servidor público (exceto professor universitário) } \\
\text { Professor universitário (servidor público ou não) } \\
\text { Profissionais liberais - assessoria/consultoria }\end{array}$}} & $\begin{array}{|lllll|}2 & 9 & 9 & 13 & 11\end{array}$ & 4 \\
\hline & 2 & & & $\begin{array}{lllll}1 & 3 & 3 & 13 & 3\end{array}$ & 4 \\
\hline & 3 & & & $\begin{array}{lllll}3 & 4 & 0 & 2 & 4\end{array}$ & 2 \\
\hline & \multicolumn{3}{|c|}{ TOTAL } & 616122818 & 4 \\
\hline & Kruskal-Wallis Test & Chi-Square $=$ & Asymp. Sig. $=$ & Ex. Sig. $=$ & 0,589 \\
\hline & $\theta n$ & Chi-Square $=$ & p. Sig. $=$ & Ex. Sig. $=$ & 0,436 \\
\hline & Rô & Coeficiente de Correlaça & com Atuação $=$ & Sig. $(2$ ext. $)=$ & 0,580 \\
\hline \multirow{7}{*}{ 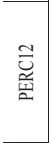 } & 1 & \multirow{3}{*}{\multicolumn{2}{|c|}{$\begin{array}{l}\text { Servidor público (exceto professor universitário) } \\
\text { Professor universitário (servidor público ou não) } \\
\text { Profissionais liberais - assessoria/consultoria }\end{array}$}} & $\begin{array}{|lllll|}6 & 6 & 13 & 13 & 6\end{array}$ & 3 \\
\hline & 2 & & & $\begin{array}{lllll}1 & 3 & 4 & 14 & 1\end{array}$ & 4 \\
\hline & 3 & & & $\begin{array}{lllll}4 & 3 & 0 & 5 & 1\end{array}$ & 2 \\
\hline & \multicolumn{3}{|c|}{ TOTAL } & 111217328 & 3,5 \\
\hline & Kruskal-Wallis Test & Chi-Square $=$ & Asymp. Sig. $=$ & Ex. Sig. $=$ & 0,270 \\
\hline & Median? & Chi-Square $=$ & Asymp. Sig. $=$ & Ex. Sig. $=$ & \\
\hline & Rô & Coeficiente de Correlaç? & com Atuação = & Sig. $(2$ ext. $)=$ & 0,889 \\
\hline \multirow{7}{*}{ 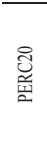 } & 1 & \multirow{3}{*}{\multicolumn{2}{|c|}{$\begin{array}{l}\text { Servidor público (exceto professor universitário) } \\
\text { Professor universitário (servidor público ou não) } \\
\text { Profissionais liberais - assessoria/consultoria }\end{array}$}} & 47711157 & 3,5 \\
\hline & 2 & & & $\begin{array}{lllll}3 & 4 & 4 & 10 & 2\end{array}$ & 4 \\
\hline & 3 & & & $\begin{array}{lllll}6 & 3 & 0 & 2 & 2\end{array}$ & 2 \\
\hline & \multicolumn{3}{|c|}{ TOTAL } & 1314152711 & 3 \\
\hline & Kruskal-Wallis Test & Chi-Square $=$ & Asymp. Sig. $=$ & Ex. Sig. $=$ & 0,089 \\
\hline & Median $T$ & Chi-Square $=$ & Asymp. Sig. $=$ & Ex. Sig. $=$ & 0,439 \\
\hline & Rô de Spearman & Coeficiente de Correlaça & com Atuação $=$ & Sig. $(2$ ext. $)=$ & 0,070 \\
\hline
\end{tabular}

Fonte: Dados da pesquisa.

Notas: Variável de agrupamento: atuação. Consistência interna das respostas deste agrupamento: $\alpha=0,932$. 
Assim, é possível afirmar que a maioria dos integrantes dos distintos grupos tem a mesma percepção concordante acerca da PERC01, dado que essas amostras são oriundas de populações com a mesma mediana $(p=0,903)$. Entre essas variáveis em análise, "atuação" e PERC01, não há correlação estatística, tendo em vista que $p$ = 0,590 > 0,05 de significância.

A descrição dos demais itens de percepção segue o mesmo raciocínio adotado para a PERC01 e, por isso, não foram detalhados. O que será destacado são as similaridades dessas variáveis.

Nesse cluster, as ramificações da PERC01, da PERC02 e da PERC03 são originadas de um mesmo nó, o que sugerem elevada proximidade, o que pode ser confirmado pelos resultados da correlação de Spearman realizado entre as variáveis. Essa similaridade está relacionada com a qualidade informacional gerada pela inclusão do atual modelo da DFC, que parece atender aos objetivos delineados no MCASP para a divulgação das demonstrações contábeis (prestação de contas e responsabilização; e tomada de decisão), assim como indica representar as especificidades do setor público brasileiro (PERC12). Porém, a percepção desses profissionais sobre a forma de apresentação do atual modelo da DFC sugere, de maneira genérica, estar adequada, clara e objetiva (PERC20) apenas para usuários internos (PERC04). Por isso, esse cluster foi denominado de "qualidade informacional interna".

\subsubsection{Agrupamento 2}

As variáveis PERC22, PERC23, PERC24 e PERC30, que integram o cluster 2 ("forma de apresentação atual"), foram agrupadas pela atuação dos participantes, conforme a Tabela 4. Pela análise dessa tabela, nota-se, por exemplo, que 66,25\% (53 de 80) dos participantes concordam a PERC30, ou seja, que os órgãos de controle (interno e externo) devem tomar providências para melhorar as informações contábeis. O grupo 1 é o que possui a maior proporção de concordantes acerca desse aspecto entre os grupos (72,72\%).

Os dados evidenciam que os grupos foram extraídos de populações com a mesma proporção $(p=0,499)$ e com as mesmas medianas $(p=0,168)$, o que levar a crer que, de forma geral, os contadores que atuam com a CASP possuem um posicionamento concordante 
à PERC30. Ao nível de significância de 0,05, há ausência de associação estatística entre essas variáveis, dado que o valor $p$ é de 0,645.

A descrição dos demais itens (PERC22, PERC23, PERC24) deste agrupamento segue o mesmo raciocínio adotado para a PERC30. O $\alpha$ do cluster 2 foi igual a 0,794, o que garante alta confiabilidade das respostas desses itens.

Tabela 4 - Cluster 2: forma de apresentação atual

\begin{tabular}{|c|c|c|c|c|c|c|c|}
\hline \multirow[b]{2}{*}{ Itens } & \multirow[b]{2}{*}{ Grupo } & \multirow{2}{*}{\multicolumn{4}{|c|}{ Atuação }} & Likert & \multirow[b]{2}{*}{ Mediana } \\
\hline & & & & & & \begin{tabular}{|l|l|l|l|l|}
1 & 2 & 3 & 4 & 5 \\
\end{tabular} & \\
\hline \multirow{7}{*}{ 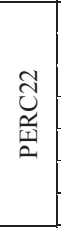 } & 1 & \multirow{3}{*}{\multicolumn{4}{|c|}{$\begin{array}{l}\text { Servidor público (exceto professor universitário) } \\
\text { Professor universitário (servidor público ou não) } \\
\text { Profissionais liberais - assessoria/consultoria }\end{array}$}} & $\begin{array}{lllll}3 & 4 & 13 & 15 & 9\end{array}$ & 4 \\
\hline & 2 & & & & & $\begin{array}{lllll}2 & 3 & 2 & 9 & 7\end{array}$ & 4 \\
\hline & 3 & & & & & $\begin{array}{lllll}1 & 2 & 4 & 2 & 4 \\
\end{array}$ & 3 \\
\hline & \multicolumn{5}{|c|}{ TOTAL } & 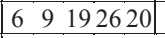 & 4 \\
\hline & Kruskal-Wallis Test & Chi-Square $=$ & 0,771 & Asymp. Sig. $=$ & 0,680 & Ex. Sig. $=$ & 0,685 \\
\hline & Median Test & Chi-Square $=$ & 1,078 & Asymp. Sig. $=$ & 0,583 & Ex. Sig. $=$ & 0,602 \\
\hline & Rô de Spearman & Coeficiente de & orrelaçấ & com Atuação = & 0,039 & Sig. $(2$ ext. $)=$ & 0,734 \\
\hline \multirow{7}{*}{$\underset{\widetilde{N}}{\tilde{N}}$} & 1 & \multirow{3}{*}{\multicolumn{4}{|c|}{$\begin{array}{l}\text { Servidor público (exceto professor universitário) } \\
\text { Professor universitário (servidor público ou não) } \\
\text { Profissionais liberais - assessoria/consultoria }\end{array}$}} & \begin{tabular}{lllll|}
4 & 4 & 17 & 12 & 7
\end{tabular} & 3 \\
\hline & 2 & & & & & $\begin{array}{lllll}3 & 4 & 4 & 6 & 6\end{array}$ & 4 \\
\hline & 3 & & & & & $\begin{array}{lllll}3 & 3 & 2 & 1 & 4 \\
\end{array}$ & 3 \\
\hline & \multicolumn{5}{|c|}{ TOTAL } & 1011231917 & 3 \\
\hline & Kruskal-Wallis Test & Chi-Square $=$ & 0,567 & Asymp. Sig. $=$ & 0,753 & Ex. Sig. $=$ & 0,757 \\
\hline & Median Test & Chi-Square $=$ & 0,762 & Asymp. Sig. $=$ & 0,683 & Ex. Sig. $=$ & 0,712 \\
\hline & Rô de Spearman & Coeficiente de & orrelaçầ & com Atuação = & $-0,041$ & Sig. $(2$ ext. $)=$ & 0,716 \\
\hline \multirow{7}{*}{ 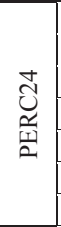 } & 1 & \multirow{3}{*}{\multicolumn{4}{|c|}{$\begin{array}{l}\text { Servidor público (exceto professor universitário) } \\
\text { Professor universitário (servidor público ou não) } \\
\text { Profissionais liberais - assessoria/consultoria }\end{array}$}} & \begin{tabular}{|llllll}
2 & 3 & 18 & 14 & 7
\end{tabular} & 3 \\
\hline & 2 & & & & & $\begin{array}{lllll}1 & 3 & 6 & 5 & 8\end{array}$ & 4 \\
\hline & 3 & & & & & $\begin{array}{lllll}1 & 3 & 4 & 1 & 4 \\
\end{array}$ & 3 \\
\hline & \multicolumn{5}{|c|}{ TOTAL } & $\begin{array}{|lllll|}4 & 9 & 28 & 20 & 19\end{array}$ & 3 \\
\hline & Kruskal-Wallis Test & Chi-Square $=$ & 1,150 & Asymp. Sig. $=$ & 0,563 & Ex. Sig. $=$ & 0,567 \\
\hline & Median Test & Chi-Square $=$ & 1,125 & Asymp. Sig. $=$ & 0,570 & Ex. Sig. $=$ & 0,618 \\
\hline & Rô de Spearman & Coeficiente de & orrelaçá & com Atuação = & 0,008 & Sig. $(2$ ext. $)=$ & 0,941 \\
\hline \multirow{7}{*}{ 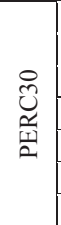 } & 1 & \multirow{3}{*}{\multicolumn{4}{|c|}{$\begin{array}{l}\text { Servidor público (exceto professor universitário) } \\
\text { Professor universitário (servidor público ou não) } \\
\text { Profissionais liberais - assessoria/consultoria }\end{array}$}} & $\begin{array}{|lllll|}2 & 3 & 7 & 16 & 16\end{array}$ & 4 \\
\hline & 2 & & & & & $\begin{array}{lllll}3 & 3 & 4 & 6 & 7\end{array}$ & 4 \\
\hline & 3 & & & & & $\begin{array}{lllll}3 & 2 & 0 & 0 & 8 \\
\end{array}$ & 5 \\
\hline & \multicolumn{5}{|c|}{ TOTAL } & $\begin{array}{|lllll|}8 & 8 & 11 & 22 & 31 \\
\end{array}$ & 4 \\
\hline & Kruskal-Wallis Test & Chi-Square $=$ & 1,410 & Asymp. Sig. $=$ & 0,494 & Ex. Sig. $=$ & 0,499 \\
\hline & Median Test & Chi-Square $=$ & 3,620 & Asymp. Sig. $=$ & 0,164 & Ex. Sig. $=$ & 0,168 \\
\hline & Rô de Spearman & Coeficiente de & orrelaça & com Atuação = & $-0,052$ & Sig. $(2$ ext. $)=$ & 0,645 \\
\hline
\end{tabular}

Fonte: Dados da pesquisa.

Notas: Variável de agrupamento: atuação. Consistência interna das respostas deste agrupamento: $\alpha=0,794$.

Ademais, percebe-se que a "qualidade informacional interna" está associada, conforme Gráfico 1 e dos outputs da correlação de Spearman entre as variáveis de percepção, com a percepção dos contadores sobre os órgãos de controle (interno e externo), no que tange a adotar medidas para melhorar as informações contábeis (PERC30), 
ou seja, que essa qualidade está adequada para usuários internos, enquanto a fiscalização não se manifesta de forma contrária. Essa mesma lógica pode ser seguida em relação ao efeito propriedade, uma vez que $50,00 \%$ dos participantes tendem a preferir escolher a forma de apresentação da DFC que eles conhecem (PERC24) ou que eles apenas seguem o que está normatizado, pois a maioria indicou concordar ou não ter um posicionamento firmado com a afirmativa de que a forma de apresentação influencia nas suas finalidades de prestação de contas e responsabilização e de tomada de decisão pelos usuários (PERC22 e PERC23).

\subsubsection{Agrupamento 3}

O cluster 3 - "tipos de usuários" - é composto pelos itens PERC05, PERC06, PERC07, PERC08, PERC09, PERC10 e PERC11. Essas variáveis, agrupadas pela atuação dos respondentes, foram apresentadas na Tabela 5. Esse agrupamento, conforme Gráfico 1, está num mesmo nível de similaridade dos agrupamentos "qualidade informacional interna" e "forma de apresentação atual" juntos.

As descrições das variáveis do cluster 3 seguem a mesma lógica dos clusters 1 e 2 . O $\alpha$ do cluster 3 foi igual a 0,900, ou seja, as respostas possuem elevada confiabilidade.

Percebe-se que a PERC05, a PERC06 e a PERC07 estão correlacionados significativamente, tendo em vista que suas ramificações partem de um mesmo nó do agrupamento "tipos de usuários". Esses itens dizem respeito à percepção desses profissionais acerca da utilização das informações do atual modelo da DFC/STN para tomada de decisão por parte de gestores, servidores e mecanismos de controle interno. 
A Percepção de Contadores Sobre a Demonstração dos Fluxos de Caixa no Setor Público Brasileiro

\section{Tabela 5 -Cluster 3: tipos de usuários}

\begin{tabular}{|c|c|c|c|c|c|c|}
\hline \multirow{2}{*}{ Itens } & \multirow{2}{*}{ Grupo } & \multirow{2}{*}{\multicolumn{3}{|c|}{ Atuação }} & Likert & \multirow{2}{*}{ diana } \\
\hline & & & & & \begin{tabular}{|l|l|l|l|l|}
1 & 2 & 3 & 4 & 5 \\
\end{tabular} & \\
\hline \multirow{7}{*}{ 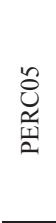 } & 1 & \multirow{3}{*}{\multicolumn{3}{|c|}{$\begin{array}{l}\text { Servidor público (exceto professor universitário) } \\
\text { Professor universitário (servidor público ou não) } \\
\text { Profissionais liberais - assessoria/consultoria }\end{array}$}} & \begin{tabular}{lllll|}
13 & 12 & 8 & 7 & 4
\end{tabular} & 2 \\
\hline & 2 & & & & $\begin{array}{lllll}6 & 2 & 7 & 5 & 3\end{array}$ & 3 \\
\hline & 3 & & & & \begin{tabular}{lllll|}
3 & 5 & 0 & 3 & 2 \\
\end{tabular} & 2 \\
\hline & \multicolumn{4}{|c|}{ TOTAL } & 221915159 & 2 \\
\hline & Kruskal-Wallis Test & Chi-Square $=$ & Asymp. Sig. $=$ & 0,541 & Ex. Sig. $=$ & 0,546 \\
\hline & Median Test & Chi-Square $=$ & Asymp. Sig. $=$ & 0,166 & Ex. Sig. $=$ & 0,178 \\
\hline & Rô de Spearman & Coeficiente de Correlaçâ & com Atuação = & 0,100 & Sig. $(2$ ext. $)=$ & 0,380 \\
\hline \multirow{7}{*}{ 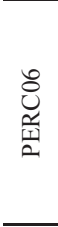 } & 1 & \multirow{3}{*}{\multicolumn{3}{|c|}{$\begin{array}{l}\text { Servidor público (exceto professor universitário) } \\
\text { Professor universitário (servidor público ou não) } \\
\text { Profissionais liberais - assessoria/consultoria }\end{array}$}} & 10138103 & 2 \\
\hline & 2 & & & & $\begin{array}{lllll}5 & 4 & 4 & 6 & 4\end{array}$ & 3 \\
\hline & 3 & & & & \begin{tabular}{lllll|}
5 & 3 & 0 & 1 & 4 \\
\end{tabular} & 2 \\
\hline & \multicolumn{4}{|c|}{ TOTAL } & 2020121711 & 2,5 \\
\hline & \begin{tabular}{|l|} 
Kruskal-Wallis Test \\
\end{tabular} & Chi-Square $=$ & Asymp. Sig. $=$ & 0,586 & Ex. Sig. $=$ & 0,591 \\
\hline & Median Test & Chi-Square $=$ & Asymp. Sig. $=$ & 0,393 & Ex. Sig. $=$ & 0,459 \\
\hline & Rô de Spearman & Coeficiente de Correlaçã & com Atuação = & 0,056 & Sig. $(2$ ext. $)=$ & 0,625 \\
\hline \multirow{7}{*}{ 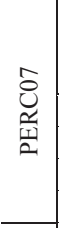 } & 1 & \multirow{3}{*}{\multicolumn{3}{|c|}{$\begin{array}{l}\text { Servidor público (exceto professor universitário) } \\
\text { Professor universitário (servidor público ou não) } \\
\text { Profissionais liberais - assessoria/consultoria }\end{array}$}} & \begin{tabular}{lllll|}
11 & 7 & 12 & 9 & 5
\end{tabular} & 3 \\
\hline & 2 & & & & \begin{tabular}{lllll|}
2 & 4 & 4 & 11 & 2
\end{tabular} & 4 \\
\hline & 3 & & & & $\begin{array}{lllll}2 & 5 & 1 & 3 & 2 \\
\end{array}$ & 2 \\
\hline & \multicolumn{4}{|c|}{ TOTAL } & 151617239 & 3 \\
\hline & Kruskal-Wallis Test & Chi-Square $=$ & Asymp. Sig. $=$ & 0,256 & Ex. Sig. $=$ & 0,258 \\
\hline & Median Test & Chi-Square $=$ & Asymp. Sig. $=$ & 0,145 & Ex. Sig. $=$ & 0,167 \\
\hline & Rô de Spearman & Coeficiente de Correlaçâ & com Atuação = & 0,106 & Sig. $(2$ ext. $)=$ & 0,349 \\
\hline \multirow{7}{*}{ 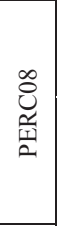 } & 1 & \multirow{3}{*}{\multicolumn{3}{|c|}{$\begin{array}{c}\text { Servidor público (exceto professor universitário) } \\
\text { Professor universitário (servidor público ou não) } \\
\text { Profissionais liberais - assessoria/consultoria }\end{array}$}} & \begin{tabular}{lllll|}
10 & 9 & 7 & 13 & 5
\end{tabular} & 3 \\
\hline & 2 & & & & $\begin{array}{lllll}3 & 5 & 4 & 10 & 1\end{array}$ & 3 \\
\hline & 3 & & & & $\begin{array}{lllll}4 & 3 & 1 & 2 & 3 \\
\end{array}$ & 2 \\
\hline & \multicolumn{4}{|c|}{ TOTAL } & 171712259 & 3 \\
\hline & \begin{tabular}{|l|} 
Kruskal-Wallis Test \\
\end{tabular} & Chi-Square $=$ & Asymp. Sig. $=$ & 0,827 & Ex. Sig. $=$ & 0,830 \\
\hline & Median Test & Chi-Square $=$ & Asymp. Sig. $=$ & 0,819 & Ex. Sig. $=$ & 0,820 \\
\hline & Rô de Spearman & Coeficiente de Correlaçâ & com Atuação = & 0,012 & Sig. $(2$ ext. $)=$ & 0,915 \\
\hline \multirow{7}{*}{$\begin{array}{l}8 \\
\substack{\frac{1}{1} \\
\frac{1}{2}}\end{array}$} & 1 & \multirow{3}{*}{\multicolumn{3}{|c|}{$\begin{array}{l}\text { Servidor público (exceto professor universitário) } \\
\text { Professor universitário (servidor público ou não) } \\
\text { Profissionais liberais - assessoria/consultoria }\end{array}$}} & \begin{tabular}{lllll|}
7 & 10 & 15 & 8 & 4
\end{tabular} & 3 \\
\hline & 2 & & & & $\begin{array}{lllll}2 & 5 & 4 & 10 & 2\end{array}$ & 4 \\
\hline & 3 & & & & \begin{tabular}{lllll|}
4 & 4 & 1 & 2 & 2 \\
\end{tabular} & 2 \\
\hline & \multicolumn{4}{|c|}{ TOTAL } & 131920208 & 3 \\
\hline & Kruskal-Wallis Test & Chi-Square $=$ & Asymp. Sig. $=$ & 0,217 & Ex. Sig. $=$ & 0,218 \\
\hline & Median Test & Chi-Square $=$ & Asymp. Sig. $=$ & 0,120 & Ex. Sig. $=$ & 0,141 \\
\hline & Rô de Spearman & Coeficiente de Correlaçâ & com Atuação = & 0,012 & Sig. $(2$ ext. $)=$ & 0,916 \\
\hline \multirow{7}{*}{$\begin{array}{l}\stackrel{0}{u} \\
\frac{n}{1} \\
\frac{1}{2}\end{array}$} & 1 & Servidor público (excet & & & $\begin{array}{lllll}3 & 9 & 15 & 14 & 3\end{array}$ & 3 \\
\hline & 2 & Professor universitário & ervidor público ou & não) & $\begin{array}{lllll}4 & 3 & 7 & 6 & 3\end{array}$ & 3 \\
\hline & 3 & Profissionais liberais & assessoria/consult & oria & \begin{tabular}{lllll|}
3 & 3 & 4 & 2 & 1 \\
\end{tabular} & 3 \\
\hline & & TOTAL & & & 101526227 & 3 \\
\hline & Kruskal-Wallis Test & Chi-Square $=$ & Asymp. Sig. $=$ & 0,398 & Ex. Sig. $=$ & 0,402 \\
\hline & Median Test & Chi-Square $=$ & Asymp. Sig. $=$ & 0,558 & Ex. Sig. $=$ & 0,564 \\
\hline & Rô de Spearman & Coeficiente de Correlaçã & com Atuação = & $-0,121$ & Sig. $(2$ ext. $)=$ & 0,285 \\
\hline & 1 & Servidor público (excet & professor universi & tário) & $\begin{array}{lllll}13 & 8 & 14 & 6 & 3\end{array}$ & 3 \\
\hline & 2 & Professor universitário & ervidor público ou & não) & $\begin{array}{lllll}6 & 6 & 5 & 5 & 1\end{array}$ & 2 \\
\hline$=$ & 3 & Profissionais liberais & assessoria/consult & oria & $\begin{array}{lllll}6 & 2 & 1 & 2 & 2 \\
\end{array}$ & 2 \\
\hline 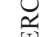 & & TOTAL & & & 251620136 & 2 \\
\hline 空 & Kruskal-Wallis Test & Chi-Square $=$ & Asymp. Sig. $=$ & 0,867 & Ex. Sig. $=$ & 0,869 \\
\hline & Median Test & Chi-Square $=$ & Asymp. Sig. $=$ & 0,678 & Ex. Sig. $=$ & 0,713 \\
\hline & Rô de Spearman & Coeficiente de Correlaçâ & com Atuação = & $-0,034$ & Sig. $(2$ ext. $)=$ & 0,766 \\
\hline
\end{tabular}

Fonte: Dados da pesquisa.

Notas: Variável de agrupamento: atuação. Consistência interna das respostas deste agrupamento: $\alpha=0,900$. 
A maioria dos respondentes discorda ou não tem opinião formada sobre a utilização dessas informações por esses usuários internos. Esse posicionamento discordante ou neutro se mantém em relação à utilização das informações da DFC pelos mecanismos de Controle Externo (PERC10) e Social (PERC11).

A PERC08 e a PERC09 estão ligadas num mesmo nó, o que indica que estão correlacionadas. O posicionamento dos contadores sobre esses itens é o mesmo das demais variáveis deste agrupamento. A maioria dos pesquisadores e professores universitários (grupo 2) é concordante com a PERC09, o que sugere que esses profissionais, no geral, estão apegados à teoria, ou seja, ao que está previsto nas normas, tendo em vista que os primeiros normativos do setor público foram herdados da área privada e abordam que a finalidade das demonstrações contábeis é serem úteis para usuários, notadamente investidores e credores, tomarem decisão. As novas NBCASP tentam mudar o foco dessa herança.

\subsubsection{Agrupamento 4}

O cluster 4 foi denominado de "controle gerencial" por ser formado pelas variáveis PERC13, PERC14, PERC19, PERC25 e PERC29 que versam sobre a percepção dos profissionais sobre o mecanismo de Fonte/Destinação de recursos no modelo da DFC/STN, sobre a segregação dos recursos em ordinários e vinculados, sobre o controle gerencial por meio da DFC e a identificação de liquidez dos entes federativos. Essas variáveis, agrupadas pela atuação dos respondentes, foram apresentadas na Tabela 6.

As descrições das variáveis do cluster 4 seguem a mesma lógica dos clusters 1, 2 e 3 e o $\alpha$ das respostas foi igual a 0,848 , o que revela alta confiabilidade dos dados. $\mathrm{O}$ "controle gerencial" está ligado, conforme Gráfico 1, ao nó que une "tipos de usuários" à "qualidade informacional interna" e "forma de apresentação atual" juntos.

De forma geral, os participantes estão divididos sobre a possibilidade de identificar a FR (PERC13) e os fluxos de recursos por meio desse mecanismo (PERC14). 47,50\% e 38,75\% das pessoas, respectivamente, concordam e discordam com a PERC13: dos concordantes, 63,16\% manifestaram de forma parcial; e dos discordantes, $67,74 \%$ sinalizaram de forma plena. Esses percentuais da PERC13 
são similares aos da PERC14 e indicam que essas variáveis estão associadas, o que pode ser ratificado pela análise do Gráfico 1 e dos outputs da correlação de Spearman entre as variáveis de percepção.

\section{Tabela 6 - Cluster 4: controle gerencial}

\begin{tabular}{|c|c|c|c|c|c|c|}
\hline \multirow{2}{*}{ Itens } & \multirow{2}{*}{ Grupo } & \multirow{2}{*}{\multicolumn{3}{|c|}{ Atuação }} & Likert & \multirow{2}{*}{ Mediana } \\
\hline & & & & & \begin{tabular}{|l|l|l|l|l|}
1 & 2 & 3 & 4 & 5 \\
\end{tabular} & \\
\hline \multirow{7}{*}{$\frac{m}{\overbrace{n}^{n}}$} & 1 & \multirow{3}{*}{\multicolumn{3}{|c|}{$\begin{array}{c}\text { Servidor público (exceto professor universitário) } \\
\text { Professor universitário (servidor público ou não) } \\
\text { Profissionais liberais - assessoria/consultoria } \\
\end{array}$}} & $\begin{array}{lllll}11 & 5 & 8 & 14 & 6\end{array}$ & 3 \\
\hline & 2 & & & & $\begin{array}{lllll}4 & 2 & 3 & 9 & 5\end{array}$ & 4 \\
\hline & 3 & & & & \begin{tabular}{lllll|}
6 & 3 & 0 & 1 & 3 \\
\end{tabular} & 2 \\
\hline & \multicolumn{4}{|c|}{ TOTAL } & 2110112414 & 3 \\
\hline & Kruskal-Wallis Test & Chi-Square $=$ & Asymp. Sig. $=$ & 0,195 & Ex. Sig. $=$ & 0,196 \\
\hline & Median Test & Chi-Square $=$ & Asymp. Sig. $=$ & 0,204 & Ex. Sig. $=$ & 0,231 \\
\hline & Rô de Spearman & Coeficiente de Correlaç & com Atuação = & $-0,026$ & Sig. $(2$ ext. $)=$ & 0,822 \\
\hline \multirow{7}{*}{$\begin{array}{l} \pm \\
\frac{\pi}{1} \\
\frac{1}{2}\end{array}$} & 1 & \multirow{3}{*}{\multicolumn{3}{|c|}{$\begin{array}{l}\text { Servidor público (exceto professor universitário) } \\
\text { Professor universitário (servidor público ou não) } \\
\text { Profissionais liberais - assessoria/consultoria }\end{array}$}} & \begin{tabular}{lllll|}
12 & 7 & 5 & 12 & 8
\end{tabular} & 3 \\
\hline & 2 & & & & $\begin{array}{lllll}4 & 3 & 3 & 9 & 4\end{array}$ & 4 \\
\hline & 3 & & & & $\begin{array}{lllll}5 & 4 & 0 & 0 & 4\end{array}$ & 2 \\
\hline & \multicolumn{4}{|c|}{ TOTAL } & 211482116 & 3 \\
\hline & Kruskal-Wallis Test & Chi-Square $=$ & Asymp. Sig. $=$ & 0,488 & Ex. Sig. $=$ & 0,492 \\
\hline & Median Test & Chi-Square $=$ & Asymp. Sig. $=$ & 0,326 & Ex. Sig. $=$ & 0,339 \\
\hline & Rô de Spearman & Coeficiente de Correlaç & com Atuação = & $-0,010$ & Sig. $(2$ ext. $)=$ & 0,929 \\
\hline \multirow{7}{*}{$\begin{array}{l}\frac{a}{u} \\
\frac{\mathscr{r}}{2} \\
\frac{1}{2}\end{array}$} & 1 & \multirow{3}{*}{\multicolumn{3}{|c|}{$\begin{array}{l}\text { Servidor público (exceto professor universitário) } \\
\text { Professor universitário (servidor público ou não) } \\
\text { Profissionais liberais - assessoria/consultoria }\end{array}$}} & $13 \quad 4 \quad 13 \quad 8 \quad 6$ & 3 \\
\hline & 2 & & & & $\begin{array}{lllll}4 & 4 & 5 & 6 & 4\end{array}$ & 3 \\
\hline & 3 & & & & \begin{tabular}{lllll|}
6 & 2 & 2 & 1 & 2 \\
\end{tabular} & 2 \\
\hline & \multicolumn{4}{|c|}{ TOTAL } & 2310201512 & 3 \\
\hline & Kruskal-Wallis Test & Chi-Square $=$ & Asymp. Sig. $=$ & 0,274 & Ex. Sig. $=$ & 0,277 \\
\hline & Median Test & Chi-Square $=$ & Asymp. Sig. $=$ & 0,425 & Ex. Sig. $=$ & 0,441 \\
\hline & Rô de Spearman & Coeficiente de Correlaç & com Atuação = & $-0,038$ & Sig. $(2$ ext. $)=$ & 0,737 \\
\hline \multirow{7}{*}{ 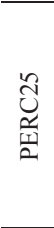 } & 1 & \multirow{3}{*}{\multicolumn{3}{|c|}{$\begin{array}{l}\text { Servidor público (exceto professor universitário) } \\
\text { Professor universitário (servidor público ou não) } \\
\text { Profissionais liberais - assessoria/consultoria }\end{array}$}} & \begin{tabular}{lllll|}
6 & 9 & 6 & 13 & 10
\end{tabular} & 4 \\
\hline & 2 & & & & $\begin{array}{lllll}5 & 2 & 4 & 9 & 3\end{array}$ & 4 \\
\hline & 3 & & & & $\begin{array}{lllll}3 & 3 & 2 & 0 & 5 \\
\end{array}$ & 3 \\
\hline & \multicolumn{4}{|c|}{ TOTAL } & 1414122218 & 3,5 \\
\hline & Kruskal-Wallis Test & Chi-Square $=$ & Asymp. Sig. $=$ & 0,891 & Ex. Sig. $=$ & 0,893 \\
\hline & Median Test & Chi-Square $=$ & Asymp. Sig. $=$ & 0,661 & Ex. Sig. $=$ & 0,749 \\
\hline & Rô de Spearman & Coeficiente de Correlaç & com Atuação = & $-0,049$ & Sig. $(2$ ext. $)=$ & 0,664 \\
\hline \multirow{7}{*}{ 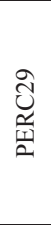 } & 1 & \multirow{3}{*}{\multicolumn{3}{|c|}{$\begin{array}{c}\text { Servidor público (exceto professor universitário) } \\
\text { Professor universitário (servidor público ou não) } \\
\text { Profissionais liberais - assessoria/consultoria }\end{array}$}} & $\begin{array}{llllll}6 & 8 & 7 & 12 & 11\end{array}$ & 4 \\
\hline & 2 & & & & $\begin{array}{lllll}4 & 4 & 3 & 5 & 7\end{array}$ & 4 \\
\hline & 3 & & & & \begin{tabular}{lllll|}
2 & 3 & 1 & 2 & 5 \\
\end{tabular} & 4 \\
\hline & \multicolumn{4}{|c|}{ TOTAL } & 1215111923 & 4 \\
\hline & Kruskal-Wallis Test & Chi-Square $=$ & Asymp. Sig. $=$ & 0,962 & Ex. Sig. $=$ & 0,963 \\
\hline & Median Test & Chi-Square $=$ & Asymp. Sig. $=$ & 0,627 & Ex. Sig. $=$ & 0,626 \\
\hline & Rô de Spearman & \multicolumn{3}{|c|}{ Coeficiente de Correlação com Atuação = } & Sig. $(2$ ext. $)=$ & 0,825 \\
\hline
\end{tabular}

Fonte: Dados da pesquisa.

Notas: Variável de agrupamento: atuação. Consistência interna das respostas deste agrupamento: $\alpha=0,848$.

Destaca-se que a maioria dos integrantes do grupo 3 possuem posicionamento discordante sobre a evidenciação da FR e também sobre a PERC19. No geral, os contadores indicaram não ter uma 
opinião formada (mediana $=3$ ) sobre se é possível identificar os recursos ordinários e os vinculados na atual estrutura da DFC/STN.

A essas três variáveis do quarto agrupamento estão ligadas a percepção sobre a PERC25 e a PERC29, que estão relacionadas num mesmo nó do Gráfico 1. Quando argumentados sobre se a DFC permite realizar o controle gerencial, 52,50\% responderam que concordam e $36,25 \%$ que discordam sobre essa questão.

Quando perguntados sobre se é possível identificar a situação de liquidez do ente público, os percentuais de concordantes e discordantes foram similares aos da PERC29, o que sugere que na percepção desses profissionais o controle gerencial está atrelado à situação de liquidez. Ao analisar o conjunto das variáveis do cluster 4, é possível supor que o controle gerencial dos recursos financeiros não está adequado para esses profissionais, tendo em vista o posicionamento neutro deles em relação à FR (PERC13 e PERC14) e a segregação do que é ou não vinculado a dada finalidade (PERC19).

\subsubsection{Agrupamento 5}

O cluster 5, por ser formado pelas variáveis PERC15, PERC16, PERC17 e PERC18, foi denominado "tipos de recursos". Essas variáveis, agrupadas pela atuação dos respondentes, foram apresentadas na Tabela 7. O $\alpha$ das respostas foi igual a 0,884 , o que revela alta confiabilidade dos dados.

As descrições das percepções que integram este agrupamento seguem a mesma das variáveis anteriores. Porém, destaca-se que, para a PERC16 e a PERC18, não há evidências de que as amostras foram extraídas de populações com a mesma distribuição, tendo em vista o $p$-valor do teste de Kruskal-Wallis desses itens. 
Tabela 7 - Cluster 5: tipos de recursos

Fonte: Dados da pesquisa.

\begin{tabular}{|c|c|c|c|c|c|c|}
\hline \multirow[b]{2}{*}{ Itens } & \multirow{2}{*}{ Grupo } & \multirow{2}{*}{\multicolumn{3}{|c|}{ Atuação }} & Likert & \multirow[b]{2}{*}{ Mediana } \\
\hline & & & & & \begin{tabular}{|l|l|l|l|l|}
1 & 2 & 3 & 4 & 5 \\
\end{tabular} & \\
\hline \multirow{7}{*}{$\begin{array}{l}n \\
\substack{n \\
\frac{1}{2}}\end{array}$} & 1 & \multirow{3}{*}{\multicolumn{3}{|c|}{$\begin{array}{c}\text { Servidor público (exceto professor universitário) } \\
\text { Professor universitário (servidor público ou não) } \\
\text { Profissionais liberais - assessoria/consultoria }\end{array}$}} & $\begin{array}{llllll}9 & 3 & 5 & 12 & 15\end{array}$ & 4 \\
\hline & 2 & & & & $\begin{array}{lllll}2 & 3 & 1 & 5 & 12\end{array}$ & 5 \\
\hline & 3 & & & & \begin{tabular}{lllll|}
2 & 2 & 0 & 1 & 8 \\
\end{tabular} & 5 \\
\hline & \multicolumn{4}{|c|}{ TOTAL } & $\begin{array}{llllll}13 & 8 & 6 & 1835\end{array}$ & 4 \\
\hline & Kruskal-Wallis Test & Chi-Square $=$ & Asymp. Sig. $=$ & 0,259 & Ex. Sig. $=$ & 0,261 \\
\hline & Median Test & Chi-Square $=$ & Asymp. Sig. $=$ & 0,135 & Ex. Sig. $=$ & 0,151 \\
\hline & Rô de Spearman & Coeficiente de Correlaçã & com Atuação = & 0,180 & Sig. $(2$ ext. $)=$ & 0,111 \\
\hline \multirow{7}{*}{ 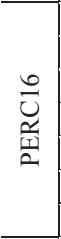 } & 1 & \multirow{3}{*}{\multicolumn{3}{|c|}{$\begin{array}{l}\text { Servidor público (exceto professor universitário) } \\
\text { Professor universitário (servidor público ou não) } \\
\text { Profissionais liberais - assessoria/consultoria }\end{array}$}} & $\begin{array}{lllll}11 & 3 & 4 & 14 & 12\end{array}$ & 4 \\
\hline & 2 & & & & $\begin{array}{lllll}2 & 2 & 2 & 8 & 9\end{array}$ & 4 \\
\hline & 3 & & & & $\begin{array}{llllll}2 & 0 & 0 & 2 & 9\end{array}$ & 5 \\
\hline & \multicolumn{4}{|c|}{ TOTAL } & 1555662430 & 4 \\
\hline & Kruskal-Wallis Test & Chi-Square $=$ & Asymp. Sig. $=$ & $0,040 *$ & Ex. Sig. $=$ & $0,039 *$ \\
\hline & Median Test & Chi-Square $=$ & Asymp. Sig. $=$ & $0,023 *$ & Ex. Sig. $=$ & $0,022 *$ \\
\hline & Rô de Spearman & Coeficiente de Correlaçã & com Atuação = & 0,279 & Sig. $(2$ ext. $)=$ & $0,012 *$ \\
\hline \multirow{7}{*}{ 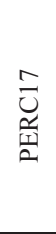 } & 1 & \multirow{3}{*}{\multicolumn{3}{|c|}{$\begin{array}{l}\text { Servidor público (exceto professor universitário) } \\
\text { Professor universitário (servidor público ou não) } \\
\text { Profissionais liberais - assessoria/consultoria }\end{array}$}} & $\begin{array}{|lllll|}4 & 2 & 6 & 14 & 18\end{array}$ & 4 \\
\hline & 2 & & & & $\begin{array}{lllll}1 & 2 & 0 & 7 & 13\end{array}$ & 5 \\
\hline & 3 & & & & \begin{tabular}{lllll|}
1 & 1 & 0 & 2 & 9 \\
\end{tabular} & 5 \\
\hline & \multicolumn{4}{|c|}{ TOTAL } & $\begin{array}{|lllll|}6 & 5 & 6 & 23 & 40 \\
\end{array}$ & 4,5 \\
\hline & Kruskal-Wallis Test & Chi-Square $=$ & Asymp. Sig. $=$ & 0,191 & Ex. Sig. $=$ & 0,193 \\
\hline & Median Test & Chi-Square $=$ & Asymp. Sig. $=$ & 0,152 & Ex. Sig. $=$ & 0,155 \\
\hline & Rô de Spearman & Coeficiente de Correlaçã & com Atuação = & 0,205 & Sig. $(2$ ext. $)=$ & 0,069 \\
\hline \multirow{7}{*}{$\begin{array}{l}\infty \\
\substack{\mathbb{1} \\
\text { II }}\end{array}$} & 1 & \multirow{3}{*}{\multicolumn{3}{|c|}{$\begin{array}{l}\text { Servidor público (exceto professor universitário) } \\
\text { Professor universitário (servidor público ou não) } \\
\text { Profissionais liberais - assessoria/consultoria }\end{array}$}} & $\begin{array}{|lllll|}4 & 2 & 7 & 14 & 17\end{array}$ & 4 \\
\hline & 2 & & & & $\begin{array}{lllll}1 & 2 & 0 & 6 & 14\end{array}$ & 5 \\
\hline & 3 & & & & $\begin{array}{lllll}1 & 0 & 0 & 2 & 10\end{array}$ & 5 \\
\hline & \multicolumn{4}{|c|}{ TOTAL } & \begin{tabular}{lllll|}
6 & 4 & 7 & 22 & 41 \\
\end{tabular} & 5 \\
\hline & Kruskal-Wallis Test & Chi-Square $=$ & Asymp. Sig. $=$ & $0,035^{*}$ & Ex. Sig. $=$ & $0,033^{*}$ \\
\hline & Median Test $t^{\mathrm{a}}$ & Chi-Square $=$ & Asymp. Sig. $=$ & & Ex. Sig. $=$ & \\
\hline & Rô de Spearman & \multicolumn{3}{|c|}{ Coeficiente de Correlação com Atuação = } & Sig. $(2$ ext. $)=$ & $0,009 * *$ \\
\hline
\end{tabular}

Notas: Variável de agrupamento: atuação. Consistência interna das respostas deste agrupamento: $\alpha=0,884 .{ }^{*}$ Significante no nível de 0,01 . *Significante no nível de

0,05. a Ao realizar o teste da mediana da PERC18 no software SPSS, foi informado que o teste não pode ser executado, tendo em vista que todos os valores são menores ou iguais à mediana e que não há casos válidos para sua execução. No software MINITAB, o Chi-Square $=7,08$ e o Asymp. Sig. $=0,029^{*}$.

Ademais, para ambas as variáveis (PERC16 e PERC18), embora se possa interpretar que pelo menos uma das medianas populacionais seja diferente das demais (teste das medianas com $p$-valor < 0,05 de significância), essa inferência pode não ser verdadeira, pois pode ocorrer ao acaso. Destaca-se também, pela correlação de Spearman, que há evidências de correlação estatística entre as variáveis ao nível de 5,00\%. 
A maioria dos participantes concorda que a DFC deve identificar os recursos orçamentários e extraorçamentários, bem como os ordinários e os vinculados. Nota-se também, a alta similaridade de respostas entre a PERC17 e a PERC18 e entre a PERC15 e a PERC16.

\subsubsection{Agrupamento 6}

A Tabela 8 apresenta as variáveis, agrupadas pela atuação dos respondentes, do último agrupamento formado: cluster 6. Por reunir a PERC21, a PERC 26, a PERC27 e a PERC28, foi denominado de "visão sobre a DFC".

Nota-se que a descrição da PERC27 acompanha o descrito sobre as variáveis PERC16 e PERC18. Destaca-se que, em relação à PERC21, as amostras provêm de populações com as mesmas proporções $(p=0,095)$, porém com medianas que não são todas iguais, dado que a estatística do teste de Kruskal-Wallis $(H=10,624)$ é superior ao valor crítico de 5,991, ao nível de significância de 0,05 ( 2 graus de liberdade). O valor p da correlação de Spearman entre a PERC21 e a "atuação" indica que há ausência de correlação estatística entre as variáveis.

Ademais, cita-se que a confiabilidade das respostas dos profissionais para as variáveis integrantes do cluster 6 é moderada, tento em vista o $\alpha=0,644$. Sobre isso, Calado e Teixeira (2016) citaram que normalmente se aceitam dados de consistência interna maiores ou iguais a $70,00 \%$.

Pelo Gráfico 1, percebe-se que há interação entre a PERC26 e a PERC27. No que tange à PERC27, a maioria dos respondentes concorda que a DFC é necessária, porém, no geral, não possuem consenso sobre se fariam a DFC, caso lhes fosse facultado elaborá-la (PERC26), dado que a mediana geral foi a classe 3. Chama a atenção que $45,45 \%$ do grupo 1 apontaram que não elaborariam esse demonstrativo, dos quais 60,00\% opinaram totalmente (classe 5). 
Tabela 8 - Cluster 6: visão sobre a DFC

\begin{tabular}{|c|c|c|c|c|c|}
\hline \multirow{2}{*}{ Itens } & \multirow{2}{*}{ Grupo } & \multirow{2}{*}{\multicolumn{2}{|c|}{ Atuação }} & Likert & \multirow{2}{*}{ Mediana } \\
\hline & & & & \begin{tabular}{|l|l|l|l|l|}
1 & 2 & 3 & 4 & 5 \\
\end{tabular} & \\
\hline \multirow{7}{*}{ 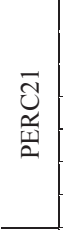 } & 1 & \multirow{3}{*}{\multicolumn{2}{|c|}{$\begin{array}{l}\text { Servidor público (exceto professor universitário) } \\
\text { Professor universitário (servidor público ou não) } \\
\text { Profissionais liberais - assessoria/consultoria }\end{array}$}} & 8 \begin{tabular}{lllll|}
8 & 7 & 9 & 15 & 5
\end{tabular} & 3 \\
\hline & 2 & & & $\begin{array}{lllll}5 & 2 & 3 & 7 & 6\end{array}$ & 4 \\
\hline & 3 & & & $\begin{array}{lllll}1 & 1 & 3 & 1 & 7 \\
\end{array}$ & 5 \\
\hline & \multicolumn{3}{|c|}{ TOTAL } & 1410152318 & 4 \\
\hline & Kruskal-Wallis Test & Chi-Square $=$ & Asymp. Sig. $=$ & Ex. Sig. $=$ & 0,095 \\
\hline & Median Test & Chi-Square $=10,624$ & Asymp. Sig. $=$ & Ex. Sig. $=$ & $0,005^{* *}$ \\
\hline & Rô de Spearman & Coeficiente de Correlaçã & com Atuação = & Sig. $(2$ ext. $)=$ & $0,042 *$ \\
\hline \multirow{7}{*}{ 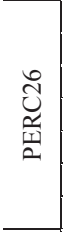 } & 1 & \multirow{3}{*}{\multicolumn{2}{|c|}{$\begin{array}{l}\text { Servidor público (exceto professor universitário) } \\
\text { Professor universitário (servidor público ou não) } \\
\text { Profissionais liberais - assessoria/consultoria }\end{array}$}} & \begin{tabular}{lllll|}
15 & 1 & 8 & 8 & 12
\end{tabular} & 3 \\
\hline & 2 & & & $\begin{array}{lllll}11 & 4 & 3 & 3 & 2\end{array}$ & 2 \\
\hline & 3 & & & $\begin{array}{lllll}4 & 2 & 2 & 1 & 4\end{array}$ & 3 \\
\hline & \multicolumn{3}{|c|}{ TOTAL } & $\begin{array}{llllll}30 & 7 & 13 & 12 & 18\end{array}$ & 3 \\
\hline & Kruskal-Wallis Test & Chi-Square $=3,979$ & Asymp. Sig. $=$ & Ex. Sig. $=$ & 0,137 \\
\hline & Median Test & Chi-Square $=$ & Asymp. Sig. $=$ & Ex. Sig. $=$ & 0,171 \\
\hline & Rô de Spearman & Coeficiente de Correlaçã & com Atuação = & Sig. $(2$ ext. $)=$ & 0,304 \\
\hline \multirow{7}{*}{ 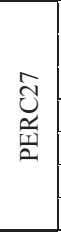 } & 1 & \multirow{3}{*}{\multicolumn{2}{|c|}{$\begin{array}{l}\text { Servidor público (exceto professor universitário) } \\
\text { Professor universitário (servidor público ou não) } \\
\text { Profissionais liberais - assessoria/consultoria }\end{array}$}} & \begin{tabular}{lllll|}
30 & 5 & 5 & 3 & 1
\end{tabular} & 1 \\
\hline & 2 & & & $\begin{array}{lllll}17 & 2 & 2 & 2 & 0\end{array}$ & 1 \\
\hline & 3 & & & \begin{tabular}{lllll|}
4 & 1 & 1 & 1 & 6 \\
\end{tabular} & 4 \\
\hline & \multicolumn{3}{|c|}{ TOTAL } & \begin{tabular}{lllll|}
51 & 8 & 8 & 6 & 7 \\
\end{tabular} & 1 \\
\hline & Kruskal-Wallis Test & Chi-Square $=$ & Asymp. Sig. $=$ & Ex. Sig. $=$ & $0,002 * *$ \\
\hline & Median Test & Chi-Square $=$ & Asymp. Sig. $=$ & Ex. Sig. $=$ & $0,025^{*}$ \\
\hline & Rô de Spearman & Coeficiente de Correlaçã & com Atuação = & Sig. $(2$ ext. $)=$ & $0,028 *$ \\
\hline \multirow{7}{*}{$\begin{array}{l}\stackrel{\infty}{\sim} \\
\frac{\sim}{1} \\
\frac{1}{2}\end{array}$} & 1 & \multirow{3}{*}{\multicolumn{2}{|c|}{$\begin{array}{l}\text { Servidor público (exceto professor universitário) } \\
\text { Professor universitário (servidor público ou não) } \\
\text { Profissionais liberais - assessoria/consultoria }\end{array}$}} & $\begin{array}{llllll}4 & 4 & 7 & 12 & 17\end{array}$ & 4 \\
\hline & 2 & & & $\begin{array}{lllll}7 & 1 & 3 & 6 & 6\end{array}$ & 4 \\
\hline & 3 & & & $\begin{array}{lllll}3 & 0 & 0 & 4 & 6 \\
\end{array}$ & 4 \\
\hline & \multicolumn{3}{|c|}{ TOTAL } & 145102229 & 4 \\
\hline & Kruskal-Wallis Test & Chi-Square $=$ & Asymp. Sig. $=$ & Ex. Sig. $=$ & 0,247 \\
\hline & Median Test & Chi-Square $=$ & Asymp. Sig. $=$ & Ex. Sig. $=$ & 0,454 \\
\hline & Rô de Spearman & \multicolumn{2}{|c|}{ Coeficiente de Correlação com Atuação = } & Sig. $(2$ ext. $)=$ & 0,594 \\
\hline
\end{tabular}

Fonte: Dados da pesquisa.

Notas: Variável de agrupamento: atuação. Consistência interna das respostas deste agrupamento: $\alpha=0,644 .{ }^{* *}$ Significante no nível de 0,01 .

*Significante no nível de 0,05 .

Ambas, PERC26 e PERC27, ligam-se à PERC21 nesse cluster, cujos dados apontam que $51,25 \%$ dos respondentes concordam que a DFC deve ter outra forma de representação. Desses concordantes, $57,00 \%$ opinaram de forma parcial (classe 4 ), o que pode sugerir que eles entendem que o atual modelo precisa ser melhorado e não substituído por completo.

Observa-se ainda que 63,75\% dos dados apontam que a DFC é feita por obediência normativa (PERC28). A maior proporção de concordantes ocorreu no grupo 3 (76,92\%), seguida pelo grupo 1 (65,91\%). As respostas do grupo 1 à PERC28 estão corroboram ao que eles opinaram em relação à PERC26. 


\subsubsection{Diferenças entre as variáveis de percepção nos grupos}

O fato dos grupos 1, 2 e 3 terem, em conjunto, apresentado distribuições diferentes nas PERC16, PERC18 e PERC27 conduziu a investigação das diferenças de percepção nos grupos de respondentes. Assim, o teste de Kruskal-Wallis foi aplicado nas amostras de respondentes, duas a duas.

Os resultados apontaram que não há diferenças entre as percepções dos integrantes dos grupos 1 e 2, conforme resultado do teste de Kruskal-Wallis entre os grupos 1 e 2. Quando esse teste foi aplicado aos dados dos grupos 1 e 3, conforme resultado do teste de Kruskal-Wallis entre os grupos 1 e 3, contatou-se que há diferenças de percepções nas variáveis PERC16, PERC18, PERC20 e PERC21, ao nível de 5,00\% de significância, e na variável PERC27, ao nível de 0,01. Em relação à PERC27, também houve diferença de percepção, ao nível de 0,01 de significância, entre os grupos 2 e 3 (conforme resultado do teste de Kruskal-Wallis entre os grupos 2 e 3).

Ou seja, os resultados da análise conjunta dos três grupos mascararam as diferenças de percepção entre os grupos 1 e 3, no que tange à PERC20 e à PERC21. Nas PERC16, PERC18 e PERC21 existe uma maior proporção de concordantes do que discordantes e neutros no grupo 3, em relação ao grupo 1.

Na PERC20 ocorre o inverso: existe uma maior proporção de discordantes do que concordantes e neutros no grupo 3, em relação ao grupo 1. Na PERC27, a mediana das respostas dos grupos 1 e 2 foi a classe 1, enquanto que a do grupo 3 foi a classe 4, ou seja, a maioria dos profissionais liberais entendem que a DFC é desnecessária, enquanto a maioria dos demais respondentes têm opinião contrária.

\subsubsection{Discussões gerais sobre os itens de percepção}

Conforme foi descrito, em 90,00\% dos itens analisados (exceto PERC16, PERC18 e PERC27), pelo teste de Kruskal-Wallis, não se rejeitou a hipótese nula de amostras que foram geradas de populações com a mesma distribuição, o que possibilita realizar inferências sobre o teste de igualdade das medianas para essas variáveis. Para cada um desses vinte e sete itens de percepção, considerando o nível de significância de 0,05 , há evidências de ausência de correlação 
estatística com a variável atuação. Apenas na PERC21 rejeitou-se a hipótese nula de que as amostras provêm de populações com medianas iguais.

Nos outros três itens (PERC16, PERC18 e PERC27), como há evidências de que as amostras provêm de populações com distribuições que não são todas iguais, não é possível fazer inferências sobre as medianas populacionais. A hipótese alternativa de que pelo menos uma mediana populacional é diferente das demais pode ocorrer ao acaso. Nesses aspectos, houve indicação de associação estatística com a variável atuação. De modo geral, as diferenças de percepções observadas na PERC16, na PERC18 e na PERC27 ocorreram entre contadores dos grupos 1 e 3.

Em relação às percepções, conforme a descrição realizada nas subseções 4.2.1 à 4.2.7, notam-se, de forma geral, opiniões conflitantes acerca de alguns itens. De um lado, esses profissionais sinalizaram que a qualidade informacional das DCASP melhorou com a inclusão da DFC/STN (PERC01), que suas informações são adequadas com o seu papel informacional (PERC02), para a tomada de decisão (PERC03) e para representar adequadamente as especificidades do setor público brasileiro (PERC12), sendo compreensíveis para usuários internos (PERC04). De outro, estão divididos quanto à compreensibilidade da DFC/STN para usuários externos (PERC08), sobre a identificação dos recursos e de seus fluxos pelo mecanismo de FR (PERC13 e PERC14) e se é possível segregar os recursos ordinários dos vinculados (PERC19).

A opinião deles sobre a PERC19 possui correlação estatística com a percepção deles sobre a identificação dos recursos ordinários (PERC17) e vinculados (PERC18), respectivamente, ao nível de 0,05 e 0,01 de significância. Ou seja, eles entendem que esses recursos devam ser identificados, mas estão indecisos sobre se a DFC/STN permite segregá-los.

Se o objetivo das DCASP é fornecer informações úteis sobre o ente público que reporta a informação, com o intuito de auxiliar seus diversos usuários na tomada de decisão, bem como na prestação de contas e na responsabilização (STN, 2017), o fato de não haver consenso entre os contadores que atuam com a CASP sobre a utilidade da DFC para usuários externos e sobre as especificidades 
do setor público brasileiro parece ir de encontro às características qualitativas informação contábil, notadamente a da relevância, da representação fidedigna e da compreensibilidade. $\mathrm{O}$ fato de tratar o mecanismo de FR apenas como informação complementar (gerencial) pode ter influenciado nas respostas dos servidores públicos que não são professores, dado que esses profissionais são usuários internos (que podem lidar com essas informações no dia a dia) e que a proporção entre concordantes e discordantes é equivalente.

Ademais, mesmo opinando que a qualidade das informações da atual estrutura da DFC/STN é adequada com o seu papel informacional (PERC02) e para a tomada de decisão (PERC03), esses contadores, mesmo havendo divergências entre alguns deles, apontaram que esse demonstrativo deve ter outra forma de apresentação (PERC21), sendo feito por obediência normativa (PERC28). Essa percepção em relação à PERC02 e à PERC03 está relacionada estatisticamente com a opinião concordante da maioria deles sobre o papel dos mecanismos de controle interno e externo, no que tange à adoção de medidas para melhorar as informações contábeis (PERC30), ou seja, que a qualidade está adequada enquanto a fiscalização não se manifesta de forma contrária.

Isso não quer dizer que esses mecanismos de controle são exclusivos na adoção de medidas para melhorar as informações evidenciadas na DFC, mas que a opinião deles parece interessar a esses profissionais. Além disso, quando argumentados sobre se a forma atual da DFC/STN influencia na compreensão do conteúdo informacional (PERC22) e na tomada de decisão pelos usuários (PERC23), a maioria sinalizou concordar ou não se posicionar em relação a esses aspectos.

De forma geral, este trabalho ratifica a pesquisa de Calado e Teixeira (2016), que sugerem haver resistência em relação à DFC e que esta demonstração é divulgada por obrigação normativa, devido, provavelmente, à baixa adaptação cultural e no ambiente de trabalho. Além disso, suas informações parecem não ser compreensíveis para os usuários externos, além de ser um demonstrativo em que os profissionais contábeis possuem discordância, conforme Calado e Teixeira (2016) propuseram. 
A similaridade com a pesquisa de Calado e Teixeira (2016) também é observada na experiência na área dos respondentes, pela análise do perfil desta pesquisa, dado que a média do tempo de formação de atuação com CASP é de 13,19 anos e que a mediana é de 11 anos. Esse resultado pode indicar, mesmo não sendo objeto de estudo nesta pesquisa, que outros fatores, como a cultura organizacional e a forma como esses profissionais encaram as novas normas, podem ser obstáculo na evidenciação das demonstrações contábeis, conforme apontaram Calado e Teixeira (2016).

Além disso, mesmo não tendo sido conduzida na forma de experimento, aponta que a forma de apresentação desse demonstrativo pode influenciar no processo de tomada de decisão por parte dos usuários, conforme apontaram Klammer e Reed (1990), Goyal (2004), Orpurt e Zang (2009), Bradbury (2011), Kojima (2012), Zhao (2013), Zhao e El-Masry (2013), Ramlugun e Hosanee (2014), Abdullah, Majed e Aymen (2016). Pela metodologia adotada, não é possível ratificar ou refutar a hipótese de que alguns usuários não se baseiam nas informações contidas na DFC para tomar decisões, nem mesmo em outros relatórios financeiros, conforme fez Kwok (2002), nem mesmo garantir que a informação pelos fluxos de caixa tem mais utilidade, relevância e objetividade para tomada de decisão do que as pautadas no regime de competência, conforme Sharma e Iselin (2003a; 2003b).

A desagregação de informações pelo mecanismo de Fonte/Destinação de recursos ainda é um ponto de indecisão, embora a maioria concorde que os recursos orçamentários e extraorçamentários, bem como os ordinários e os vinculados devam ser evidenciados. Isso não corrobora, nem refuta os trabalhos de Libby e Brown (2013) e de Bonner, Clor-Proell e Koonce (2014), em relação aos gestores desagregarem informações quando lhes for conveniente.

Por fim, não é possível corroborar com o estudo de Carvalho et al. (2013), de que os respondentes tendem a preferir o modelo de apresentação que eles conhecem, dado que não foram testadas, no mínimo, duas estruturas de DFC e também pela opinião nas respostas. Porém, revelou que esses profissionais endentem ser adequado haver outra forma de apresentação da DFC para as entidades do setor público brasileiro. 
As causas que levaram essas pessoas a se posicionarem assim não estão claras e carecem de estudos. Independente disso, na próxima seção foi proposta uma estrutura alternativa para a DFC do setor público, que deve ser entendida como uma sugestão de melhoria ao atual modelo da STN. Destaca-se que esse modelo de DFC da União foi um avanço para a CASP, no sentido de abrir caminho para a transparência das informações financeiras dos entes federados e para a adequação aos padrões internacionais de contabilidade.

\section{CONSIDERAÇões Finais}

Esta pesquisa teve o objetivo de verificar a percepção de contadores que atuam com a Contabilidade Aplicada ao Setor Público (CASP) acerca da evidenciação da Demonstração dos Fluxos de Caixa (DFC), conforme modelo da Secretaria do Tesouro Nacional (STN). Inicialmente, identificou-se que a amostra de respondentes é, de maneira geral, homogênea no que tange aos aspectos de perfil. O tempo de formação em Ciências Contábeis e de experiência profissional deles é bem diversificado, não sendo a média um bom parâmetro de medida de posição para essas variáveis.

Os resultados, de forma geral, apontaram que os contadores ainda possuem dúvidas em relação à DFC e que divergem em alguns pontos, mesmo considerando que a maioria possui algum tipo de pós-graduação concluída. Essas opiniões divergentes em relação a alguns dos trinta itens de percepção são ratificadas pelo número de clusters formados: seis.

Esses clusters foram denominados: "qualidade informacional interna"; "forma de apresentação atual"; "tipos de usuários"; "controle gerencial"; "tipos de recursos"; e "visão sobre a DFC". À exceção dos dados do agrupamento "visão sobre a DFC", que possui confiabilidade de 0,644 , todos os demais possuem alfa de Cronbach maior que $70,00 \%$.

Quando segregados pela atuação dos respondentes, foi observado que há diferenças estatísticas significativas entre a opinião deles sobre a identificação e evidenciação dos recursos extraorçamentários e dos recursos vinculados na DFC, bem como se a DFC é ou não necessária. Em relação a esse último aspecto, a percepção dos profissionais liberais diverge dos demais respondentes. 
No geral, a maioria sugeriu que essa demonstração deveria: ter outra forma de apresentação; e identificar os recursos ordinários e vinculados, bem como os orçamentários e extraorçamentários. Em relação às divergências nas respostas, seria interessante investigar as causas que levam distintos profissionais que atuam com a CASP, de forma prática ou teórica, a terem percepções diferentes sobre uma mesma informação acerca da DFC, como a formação de cada um deles ou até mesmo a não reflexão acerca da melhoria das demonstrações contábeis. O grupo de profissionais liberais foi o que apresentou maiores dissimilaridades nas respostas em relação ao grupo dos contadores que são servidores públicos (exceto professores universitários).

O grupo dos professores universitários, que são ou não servidores públicos, demonstrou ser mais otimista em relação à utilização e a compreensibilidade das informações da DFC, conforme modelo da STN, para usuários internos. Outro ponto que é possível de análise é o desenvolvimento de experimentos, similares aos desenvolvidos nas pesquisas citadas neste estudo, que trabalhem com a informação agregada e com a desagregada pelo método direto, ou com a apresentação das informações pelos métodos direto e indireto, de tal forma a captar percepções de usuários e buscar melhorias para esse demonstrativo.

A busca de melhorias nos demonstrativos contábeis visa contribuir com o planejamento orçamentário e fiscal, com o controle dos gastos públicos, com a prestação de contas, com a responsabilização dos gestores de recursos públicos e com a tomada de decisão por parte dos usuários das informações do setor público. Ademais, visa reduzir a assimetria informacional entre o Governo e as partes interessadas, ao melhorar a qualidade e transparência das informações dos entes governamentais, conforme preconiza as normas internacionais de contabilidade e a legislação brasileira.

Assim, a maior restrição deste trabalho foi o número de respondentes da amostra e, consequentemente, dos grupos. Sugerem-se novas pesquisas sobre a percepção dos contadores que militam na área da Contabilidade Aplicada ao Setor Público, seja em relação à forma de apresentação das demonstrações contábeis, seja em relação à qualidade das informações divulgadas à sociedade. Sugerem-se 
também pesquisas que procurem desenvolver indicadores de análise para a DFC, bem como que busquem realizar comparações entre entes federados com características similares.

\section{REFERÊNCIAS}

ABDULLAH, S. H.; MAJED, A. Q.; AYMEN, M. A. The preference of direct or indirect methods in preparing the statement of cash flows in decision making: an academic perspective. International Journal of Economics and Finance, v. 8, n. 2, p. 206-214, 2016.

ABEYSINGHE, C.; SAMANTHI, D. Accrual basis and political interest in public sector accounting. The case of a municipal council in Sri Lanka. International Journal of Academic Research in Accounting, Finance and Management Sciences, v. 6, n. 3, p. 58-68, 2016.

ADHIKARI, P.; GÅRSETH-NESBAKK, L. Implementing public sector accruals in OECD member states: Major issues and challenges. Accounting Forum, v. 40, n. 2, p. 125-142, 2016.

ALSHUJAIRI, M. H. A. Government accounting system reform and the adoption of IPSAS in Iraq. Research Journal of Finance and Accounting, v. 5, n. 24, p. 1-20, 2014.

AVERSANO, N.; CHRISTIAENS, J. Governmental financial reporting of heritage assets from a user needs perspective. Financial Accountability \& Management, v. 30, n. 2, p. 150-174, 2014.

BEZERRA FILHO, J. E. Orçamento aplicado ao setor público: abordagem simples e objetiva. 2. ed. São Paulo: Atlas, 2013.

BONNER, S. E.; CLOR-PROELL, S. M.; KOONCE, L. Mental accounting and disaggregation based on the sign and relative magnitude of income statement items. The Accounting Review, v. 89, n. 6, p. 2087-2114, 2014.

BRADBURY, M. Direct or indirect cash flow statements?. Australian Accounting Review, v. 21, n. 2, p. 124-130, 2011.

CALADO, J. E. de S.; TEIXEIRA, A. M. C. Demonstrações contábeis no setor público brasileiro: a percepção dos profissionais que elaboram as informações. Contabilidade, Gestão e Governança, Brasília, v. 19, n. 3, p. 485-503, 2016.

CARVALHO, V. G. de; SILVA, J. J. da; MENDES, C. J. F.; SILVA, J. D. G. da. A forma como o balanço patrimonial é apresentado altera a percepção do usuário externo quanto à interpretação do conteúdo informacional? Uma investigação no contexto brasileiro e cabo-verdiano. Revista Contemporânea de Contabilidade, Florianópolis, v. 10, n. 21, p. 71-86, 2013.

CARVALHO JUNIOR, C. V. de O.; CORNACCHIONE, E.; ROCHA, A. F. da; ROCHA, F. T. Mapeamento cognitivo cerebral de auditores e contadores em julgamentos de continuidade operacional. Revista Contabilidade \& Finanças, São Paulo, v. 28, n. 73, p. 132-147, 2017.

CHRISTIAENS, J.; REYNIERS, B.; ROLLÉ, C. Impact of IPSAS on reforming governmental financial information systems: a comparative study. International Review of Administrative Sciences, v. 76, n. 3, p. 537-554, 2010.

; VANHEE, C.; MANES-ROSSI, F.; AVERSANO, N.; CAUWENBERGE, P. Van. The effect of IPSAS on reforming governmental financial reporting: An international comparison. International Review of Administrative Sciences, v. 81, n. 1, p. 158-177, 2015. 
DAGA, K.; KRUGER, S. D.; MAZZIONI, S. Demonstração dos fluxos de caixa: controle gerencial ou obediência normativa? Revista de Contabilidade da UFBA, Salvador, v. 9, n. 1, p. 93-112, 2015.

FERNANDES, E. S.; BEZERRA FILHO, J. E. Subsistema de informação de custos no setor público: proposta de um modelo de mensuração e acumulação com base no regime de competência. Advances in Scientific and Applied Accounting, São Paulo, v. 9, n. 2, p. 204-223, 2016.

GOYAL, M. K. A survey on popularity of the direct method of cashflow reporting. Journal of Applied Management Accounting Research, v. 2, n. 2, p. 41-52, 2004.

GROSSI, G.; SOVERCHIA, M. European Commission Adoption of IPSAS to reform financial reporting. Abacus, v. 47, n. 4, p. 525-552, 2011.

HOEK, M. P. Van Der. From cash to accrual budgeting and accounting in the public sector: The Dutch experience. Public Budgeting \& Finance, v. 25, n. 1, p. 32-45, 2005.

HOMERO JUNIOR, P. F. Crítica metodológica e epistemológica de pesquisas contábeis experimentais publicadas no Brasil. Revista de Educação e Pesquisa em Contabilidade, Brasília, v. 10, n. 2, p. 220-233, 2016.

INTERNATIONAL FEDERATION OF ACCOUNTANTS - IFAC. IPSAS 2 - cash flow statements. In: Handbook of international public sector accounting pronouncements. (2016 edition, volume I). New York, US: IPSASB®, 2016. p. 217-242. Disponível em: <https:// www.iaasb.org/system/files/publications/files/IPSASB-2016-Handbook-Volume-1.pdf >. Acesso em: 6 out. 2016.

JONES, R.; CARUANA, J. A perspective on the proposal for European Public Sector Accounting Standards, in the context of accruals in UK government accounting. Accounting, Economics and Law, v. 4, n. 3, p. 265-282, 2014.

KLAMMER, T. P.; REED, S. A. Operating cash flow formats: does format influence decisions?. Journal of Accounting and Public Policy, v. 9, n. 3, p. 217-235, 1990.

KOJIMA, K. Decision usefulness of cash flow information format: An experimental study. International Review of Business, n. 12, p. 23-44, 2012.

KWOK, H. The effect of cash flow statement format on lenders' decisions. The International Journal of Accounting, v. 37, n. 3, p. 347-362, 2002.

LASWAD, F.; REDMAYNE, N. B. IPSAS or IFRS as the framework for public sector financial reporting? New Zealand preparers' perspectives. Australian Accounting Review, v. 25, n. 2, p. 175-184, 2015.

LIBBY, R.; BROWN, T. Financial statement disaggregation decisions and auditors' tolerance for misstatement. The Accounting Review, v. 88, n. 2, p. 641-665, 2013.

MALAQUIAS, R. F.; MACHADO, T. R. B.; SÁ, F. F. Expressões de incerteza em pronunciamentos contábeis: há algum efeito do tempo nas diferenças de percepção?. Revista Contabilidade, Gestão e Governança, Brasília, v. 20, n. 1, p. 20-37, 2017.

MARÔCO, J. Análise estatística com o SPSS Statistics. 6. ed. Portugal: Perô Pinheiro. 2014.

MARTINS, G. de A.; DOMINGUES, O. Estatística geral e aplicada. 4. ed. rev. e ampl. São Paulo: Atlas. 2011. 
MUSSARI, R. EPSAS and the unification of public sector accounting across Europe. Accounting, Economics and Law, v. 4, n. 3, p. 299-312, 2014.

ORPURT, S. F.; ZANG, Y. Do direct cash flow disclosures help predict future operating cash flows and earnings?. The Accounting Review, v. 84, n. 3, p. 893-935, 2009.

OULASVIRTA, L. O. Governmental financial accounting and european harmonisation: case study of Finland. Accounting, Economics and Law, v. 4, n. 3, p. 237-263, 2014a.

. The reluctance of a developed country to choose International Public Sector Accounting Standards of the IFAC. A critical case study. Critical Perspectives on Accounting, v. 25, n. 3, p. 272-285, 2014b.

PICCOLI, M. R.; KLANN, R. C. A percepção dos contadores públicos em relação às Normas Brasileiras de Contabilidade Aplicadas ao Setor Público (NBCASP). Revista do Serviço Público, Brasília, v. 66, n. 3, p. 425-448, 2015.

RAMLUGUN, V. G.; HOSANEE, P. Users' perception on cash flow reporting practices in Mauritius. Studies in Business and Economics, v. 9, n. 3, p. 82-96, 2014.

RODRIGUES, A.; PAULO, E. Introdução à análise multivariada. In CORRAR, Luiz J.; PAULO, Edilson; DIAS FILHO, José Maria. (Coord.). Análise multivariada: para os cursos de administração, ciências contábeis e economia. 1. ed. 4. reimpr. São Paulo: Atlas, 2012, p. 1-72.

ROSA, F. S. da; SILVA, L. C. da; SOARES, S. V. Aspectos de convergência da contabilidade no setor público: um enfoque sobre a implantação do sistema de custos segundo a percepção de contadores municipais do estado de Santa Catarina. Contabilidad y Negocios, v. 10, n. 19, p. 27-42, 2015.

SECRETARIA DO TESOURO NACIONAL. Manual de contabilidade aplicada ao setor público: Aplicado à União, aos estados, ao Distrito Federal e aos municípios. 7. ed. STN: Brasília, 2017.

SHARMA, D. S.; ISELIN, E. R. The decision usefulness of reported cash flow and accrual information in a behavioural field experiment. Accounting and Business Research, v. 33, n. 2, p. 123-135, 2003a.

The relative relevance of cash flow and accrual information for solvency assessments: a multi-method approach. Journal of Business Finance \& Accounting, v. 30, n. 7-8, p. 1115-1140, 2003b.

SILVA, J. P. da; NIYAMA, J. K.; RODRIGUES, A. M. Análise da percepção dos participantes do processo normativo do IASB sobre a proposta de revisão da estrutura conceitual. Advances in Scientific \& Applied Accounting, São Paulo, v. 9, n. 3, p. 243-261, 2016.

ZHAO, L. Does the presentation format of the statement of cash flows affect analysts' cash flow forecast. The Journal of International Management Studies, v. 8, n. 2, p. 49-53, 2013.

; EL-MASRY, E. E. Assessing the ability of the direct method format of the statement of cash flows to boost financial analysts judgment accuracy. The Journal of Human Resource and Adult Learning, v. 9, n. 2, p. 1-7, 2013.

Recebido em: 23-8-2019

Aprovado em: 12-12-2020

Avaliado pelo sistema double blind review.

Disponível em http://mjs.metodista.br/index.php/roc 